\title{
Remote sensing of LAI, chlorophyll and leaf nitrogen pools of crop- and grasslands in five European landscapes
}

\author{
E. Boegh ${ }^{1}$, R. Houborg ${ }^{2}$, J. Bienkowski ${ }^{3}$, C. F. Braban ${ }^{4}$, T. Dalgaard ${ }^{5}$, N. van Dijk ${ }^{4}$, U. Dragosits ${ }^{4}$, E. Holmes ${ }^{1}$, \\ V. Magliulo ${ }^{6}$, K. Schelde ${ }^{5}$, P. Di Tommasi ${ }^{6}$, L. Vitale $^{6}$, M. R. Theobald ${ }^{4,7}$, P. Cellier ${ }^{8}$, and M. A. Sutton ${ }^{4}$ \\ ${ }^{1}$ Roskilde University, Dept. of Environmental, Social and Spatial Change, Roskilde, Denmark \\ ${ }^{2}$ King Abdullah University of Science and Technology, Water Desalination and Reuse Center, Thuwal, \\ Kingdom of Saudi Arabia \\ ${ }^{3}$ Institute for Agricultural and Forest Environment, Polish Academy of Sciences, Poznan, Poland \\ ${ }^{4}$ Centre for Ecology and Hydrology, Edinburgh Research Station, Penicuik, UK \\ ${ }^{5}$ Aarhus University, Dept of Agroecology, Tjele, Denmark \\ ${ }^{6}$ CNR ISAFoM, Napoli, Italy \\ ${ }^{7}$ Technical University of Madrid, E. T. S. I Agrónomos, Madrid, Spain \\ ${ }^{8}$ INRA, UMR1091 Environnement et Grandes Cultures, Thiverval-Grignon, France
}

Correspondence to: E. Boegh (eboegh@ruc.dk)

Received: 10 July 2012 - Published in Biogeosciences Discuss.: 2 August 2012

Revised: 16 August 2013 - Accepted: 19 August 2013 - Published: 7 October 2013

\begin{abstract}
Leaf nitrogen and leaf surface area influence the exchange of gases between terrestrial ecosystems and the atmosphere, and play a significant role in the global cycles of carbon, nitrogen and water. The purpose of this study is to use field-based and satellite remote-sensing-based methods to assess leaf nitrogen pools in five diverse European agricultural landscapes located in Denmark, Scotland (United Kingdom), Poland, the Netherlands and Italy. REGFLEC (REGularized canopy reFLECtance) is an advanced image-based inverse canopy radiative transfer modelling system which has shown proficiency for regional mapping of leaf area index (LAI) and leaf chlorophyll $\left(\mathrm{CHL}_{1}\right)$ using remote sensing data. In this study, high spatial resolution (10-20 m) remote sensing images acquired from the multispectral sensors aboard the SPOT (Satellite For Observation of Earth) satellites were used to assess the capability of REGFLEC for mapping spatial variations in $\mathrm{LAI}, \mathrm{CHL}_{1}$ and the relation to leaf nitrogen $\left(\mathrm{N}_{1}\right)$ data in five diverse European agricultural landscapes. REGFLEC is based on physical laws and includes an automatic model parameterization scheme which makes the tool independent of field data for model calibration. In this study, REGFLEC performance was evaluated using LAI measurements and non-destructive measurements (using a SPAD meter) of leaf-scale $\mathrm{CHL}_{1}$ and
\end{abstract}

$\mathrm{N}_{1}$ concentrations in 93 fields representing crop- and grasslands of the five landscapes. Furthermore, empirical relationships between field measurements (LAI, $\mathrm{CHL}_{1}$ and $\mathrm{N}_{1}$ ) and five spectral vegetation indices (the Normalized Difference Vegetation Index, the Simple Ratio, the Enhanced Vegetation Index-2, the Green Normalized Difference Vegetation Index, and the green chlorophyll index) were used to assess field data coherence and to serve as a comparison basis for assessing REGFLEC model performance. The field measurements showed strong vertical $\mathrm{CHL}_{1}$ gradient profiles in $26 \%$ of fields which affected REGFLEC performance as well as the relationships between spectral vegetation indices (SVIs) and field measurements. When the range of surface types increased, the REGFLEC results were in better agreement with field data than the empirical SVI regression models. Selecting only homogeneous canopies with uniform $\mathrm{CHL}_{1}$ distributions as reference data for evaluation, REGFLEC was able to explain $69 \%$ of LAI observations $($ rmse $=0.76), 46 \%$ of measured canopy chlorophyll contents $\left(\mathrm{rmse}=719 \mathrm{mg} \mathrm{m}^{-2}\right.$ ) and $51 \%$ of measured canopy nitrogen contents $\left(\mathrm{rmse}=2.7 \mathrm{~g} \mathrm{~m}^{-2}\right)$. Better results were obtained for individual landscapes, except for Italy, where REGFLEC performed poorly due to a lack of dense vegetation canopies at the time of satellite recording. Presence of 
vegetation is needed to parameterize the REGFLEC model. Combining REGFLEC- and SVI-based model results to minimize errors for a "snap-shot" assessment of total leaf nitrogen pools in the five landscapes, results varied from 0.6 to $4.0 \mathrm{t} \mathrm{km}^{-2}$. Differences in leaf nitrogen pools between landscapes are attributed to seasonal variations, extents of agricultural area, species variations, and spatial variations in nutrient availability. In order to facilitate a substantial assessment of variations in $\mathrm{N}_{1}$ pools and their relation to landscape based nitrogen and carbon cycling processes, time series of satellite data are needed. The upcoming Sentinel-2 satellite mission will provide new multiple narrowband data opportunities at high spatio-temporal resolution which are expected to further improve remote sensing capabilities for mapping LAI, $\mathrm{CHL}_{1}$ and $\mathrm{N}_{1}$.

\section{Introduction}

Nutrient availability is highly variable and related to land use, farming systems, soil type and topography (Duretz et al., 2011) as well as the atmospheric deposition of ammonia and nitrogen oxides (Churkina et al., 2010). Despite the excessive use of nitrogen fertilizers in many European croplands (Eurostat, 2012), water and nutrient resource availability is responsible for large inter-plant-species spatial variation in photosynthetic capacity and carbon exchange rates (Moors et al., 2010). This causes the carbon balance of fields to either be a source or a sink (Ciais et al., 2010). Remotesensing-based spectral vegetation indices (SVIs) calculated from broadband satellite sensors have been used to represent the resource constrained leaf area index (LAI) and light absorption for photosynthesis modelling (Field et al., 1995; Zhao et al., 2005a). However, the maximum light-use efficiencies as well as the maximum Rubisco capacities which are catalysing the $\mathrm{CO}_{2}$ fixation, can vary by a factor of 2 for European crops (Chen et al., 2011; Moors et al., 2010). Because the bulk of leaf nitrogen is associated with Rubisco, leaf nitrogen is considered a critical determinant of the maximum Rubisco capacity in photosynthesis modelling (e.g. Farquhar et al., 1980; dePury and Farquhar, 1997; Boegh et al., 2002; and Kattge et al., 2009), and it also plays an important role for the $\mathrm{NH}_{3}$ exchange between vegetation and the atmosphere (Mattson et al., 2009; Massad et al., 2010), which is an important component of the nitrogen $(\mathrm{N})$ cycle and closely coupled to the carbon cycle. Due to the characteristic spectral signature of leaf pigments and their $\mathrm{N}$ contents, remote sensing of leaf chlorophyll $\left(\mathrm{CHL}_{1}\right)$ and leaf nitrogen $\left(\mathrm{N}_{1}\right)$ is feasible (e.g. Blackburn, 1998; Broge and LeBlanc, , 2000; Boegh et al., 2002; Hansen and Schjoerring, 2002; Sims and Gamon, 2002; Gitelson et al., 2005; Zhao et al., 2005b; Houborg and Boegh, 2008; Houborg et al., 2009; Dash et al., 2010; Main et al., 2011; and Peng and Gitelson, 2012), and it has been found that such variables can be used as measures of the light-use efficiency (Houborg et al., 2011; Peng and Gitelson, 2012) and the maximum Rubisco capacity (Boegh et al., 2002) in photosynthesis modelling.

Most remote-sensing-based methods for estimating $\mathrm{CHL}_{1}$ and $\mathrm{N}_{1}$ were developed for single species using leaf-scale data to develop SVIs that are closely correlated with $\mathrm{CHL}_{1}$ and $\mathrm{N}_{1}$ (e.g. Sims and Gamon, 2002; Zhao et al., 2005b; and Main et al., 2011). As for $\mathrm{CHL}_{1}$, remote sensing of $\mathrm{N}_{1}$ performs best in the visible spectral bands. Its estimation can be indirect due to $\mathrm{N}_{1}$ association with $\mathrm{CHL}_{1}$ (Yoder and Pettigrew-Crosby, 1995), however $\mathrm{N}$ is also included in other pigments such as carotenoids and anthocyanin which have different spectral signatures than $\mathrm{CHL}_{1}$ (Sims and Gamon, 2002). In the absence of N, plants degrade their chlorophyll molecules, and $\mathrm{CHL}_{1}$ is determined by the availability of $\mathrm{N}_{1}$ (Filella et al., 1995), thereby causing a close relationship between $\mathrm{CHL}_{1}$ and $\mathrm{N}_{1}$ measurements (e.g. Boegh et al., 2002; and Zhao et al., 2005b). Physiological investment of $\mathrm{N}$ in light-harvesting $\mathrm{CHL}_{1}$ and Rubisco aims to maximize photosynthesis, and the $\mathrm{N}$ partitioning of leaves between $\mathrm{CHL}_{1}$ and Rubisco is therefore light dependent and varies with plant growth form and between species (e.g. Hallik et al., 2012). For instance, leaves grown at high light intensity tend to allocate more $\mathrm{N}$ to Rubisco, therefore increasing the photosynthetic capacity per leaf area, whereas shade-tolerant species tend to have higher $\mathrm{CHL}_{1}: \mathrm{N}_{1}$ ratios.

Photosynthesis optimization theory suggests that plants will distribute their $\mathrm{N}$ resources in proportion to the light gradient within the canopy (e.g. dePury and Farquhar, 1997). This complicates the evaluation of remote-sensing-based canopy $\mathrm{CHL}_{1}$ and $\mathrm{N}_{1}$ estimation methodologies because ground truth measurements are based on leaf-scale data. Some remote sensing studies measure $\mathrm{CHL}_{1}$ of the upper leaf, which is then multiplied by the green LAI to represent canopy chlorophyll $\left(\mathrm{CHL}_{\mathrm{c}}\right)$ content (e.g. Gitelson et al., 2005; and Atzberger et al., 2010). Other studies use random sampling (e.g. Darvishzadeh et al., 2008; and Dash et al., 2010) or integrate over the canopy height (e.g. Broge and LeBlanc, 2000). Measuring conditions at canopy and regional scales is further complicated by variations in soil background reflectance and canopy structures of the different land cover types, and it is often found that different SVIs have different capabilities for estimating LAI, CHL and N (e.g. Broge and LeBlanc, 2000). Mismatch in the spatial resolution of ground truth field data and satellite based SVIs over extended regions also challenges the evaluation of SVIs (Garrigues et al., 2008; Dash et al., 2010), and many studies have used leaf and canopy radiative transfer models (CRTMs) to study the sensitivity of SVIs when exposed to different external factors at canopy scale (e.g. Carlson and Ripley, 1997; Broge and LeBlanc, 2000; and Haboudane et al., 2004). CRTMs are physically based models that consider soil and leaf properties, stand geometry and clumping for modelling spectral surface reflectance, however the canopy is typically assumed to consist of a homogeneous layer of 
vegetation, although a two-layer version of the CRTM model, SAIL, has been developed (Verhoef and Bach, 2012). Furthermore, very few studies report on the vertical detection footprint of remote sensors (Ciganda et al., 2012; Winterhalter et al., 2012). It is well known that dense canopies effectively absorb red light, which leads to diminishing reflectance and saturation effect in the red chlorophyll peak absorption band, and that most SVIs saturate at high LAI values (e.g. Yoder and Waring, 1994; and Huete, 1988). A recent experiment aimed at detecting the vertical footprint of a red edge SVI to provide information on $\mathrm{N}_{1}$ in a maize canopy showed, however, that the remote sensor was able to detect $\mathrm{N}_{1}$ down to the lowest levels (Winterhalter et al., 2012). Another recent study showed that a SVI (the red-edge chlorophyll index) sensed only the upper 8-9 leaf layers in a maize canopy. Even though the SVI was empirically related to canopy chlorophyll content, the upper 8-9 leaf layers represented just 55-65\% of total canopy chlorophyll content (Ciganda et al., 2012).

Despite incomplete representation of within-canopy $\mathrm{CHL}_{1}$ and $\mathrm{N}_{1}$ profiles in many remote sensing data and model studies, the sensitivity of canopy reflectance to soil background reflectance and canopy geometry has been clearly demonstrated and points to the need for land-cover-specific conversions to estimate LAI from SVIs (Knyazikhin et al., 1998). Furthermore, generalized soil adjusted SVIs have been developed (Huete, 1988; Huete et al., 2002) which show improved relationships with LAI (e.g. Boegh et al., 2002; Houborg and Soegaard, 2004; and Huete et al, 2006). However, because SVIs require empirical calibration to assess $\mathrm{LAI}, \mathrm{CHL}_{1}$ and $\mathrm{N}_{\mathrm{l}}$, such calibration may not be transferable to other canopies due to variations in soil background and canopy structure. Therefore, methods have been developed to use physically based CRTMs for inverse model estimation of LAI and $\mathrm{CHL}_{1}$ (e.g. Jacquemoud et al., 2000; Darvishzadeh et al., 2008; Houborg et al., 2009; and Atzberger and Richter, 2012). The use of CRTMs is attractive because they are able to represent canopy geometry and the various radiometric properties of leaves and soils and, therefore, they do not require calibration. However, CRTMs require many soil and vegetationspecific model parameters, which may be unknown. Due to the number of unknown variables exceeding the number of radiometric variables in the input data, and because different parameter combinations can yield similar spectral reflectance simulations, the model inversion process is mathematically ill-founded (Combal et al., 2002). A priori information about model parameters or the use of additional input data types (hyperspectral or multi-angular data) can be used to constrain the model inversion, however such information may not be available at large spatial scales, and the use of additional radiometric input data can be redundant. Utilization of spatial information content within remote sensing images can be an attractive solution (e.g. Houborg and Anderson, 2009; and Atzberger and Richter, 2012). Houborg et al. (2007) developed an image-based method for $\mathrm{LAI}$ and $\mathrm{CHL}_{1}$ map- ping which included automatic parameterization of a combined leaf optics-CRTM model (PROSPECT-ACRM). The method identifies bare soil and dense vegetation fields, and the spectral signatures of these fields are then used to constrain the model inversion for class-specific parameterization. Very good results were obtained for LAI ( $\mathrm{rmse}=0.4$ 0.7 ) and leaf-scale CHL (rmse $=5-9 \mu \mathrm{g} \mathrm{cm}^{-2}$ ) when applied at a regional scale (Houborg et al., 2007; Houborg and Boegh, 2008; Houborg and Anderson, 2009), and even better results were achieved when applied to field-scale image data with $1 \mathrm{~m}$ spatial resolution (rmse $=0.25$ for LAI and $4.4 \mu \mathrm{g} \mathrm{cm}^{-2}$ for CHL) due to the efficient model parameterization scheme (Houborg et al., 2009). The method has been developed into a user-friendly tool, REGFLEC (REGularized canopy reFLECtance), which combines atmospheric and canopy radiative transfer modelling to estimate LAI and $\mathrm{CHL}_{1}$ directly from at-satellite radiance data (Houborg and Anderson, 2009).

\subsection{Objectives}

The overall purpose of this paper is to assess the differences in vegetation $\mathrm{N}$ pools of five European agricultural landscapes affiliated to the EU project NitroEurope (Sutton et al., 2007; Cellier et al., 2011) and located in Denmark, Scotland (United Kingdom), Poland, the Netherlands and Italy. Vegetation $\mathrm{N}$ pools are needed to quantify variations in resource availability for photosynthesis modelling and for nitrogen budget estimation. For this purpose, the utility of the REGFLEC approach for remote-sensing-based regional mapping of LAI, $\mathrm{CHL}_{1}$ and $\mathrm{N}_{1}$ in crop- and grasslands is assessed over the large range of environmental (atmospheric and soil) conditions characterizing the five landscapes. The REGFLEC model was applied to high spatial resolution (10-20 m) multispectral SPOT (Satellite For Observation of Earth) satellite images (Astrium, 2012). Field measurements of LAI, $\mathrm{CHL}_{1}$ and $\mathrm{N}_{1}$ were collected for cropand grasslands in each landscape. Field data coherency was assessed by comparison with five different SVIs which are known to be closely related to LAI and chlorophyll. Finally, the spatial variations in vegetation $\mathrm{N}$ pools of the landscapes were quantified and discussed using field data and the high spatial resolution SPOT satellite images.

\subsection{Overview}

The five landscapes are presented in Sect. 2. Satellite and field data are described in the Methods Sects. 3.1 and 3.2, the SVIs are presented in Sect. 3.3, and the REGFLEC approach is described in Sect. 3.4. The Results section presents first landscape-scale variations in terms of observed vegetation seasonality and LAI measurements at the time of SPOT satellite passage (Sect. 4.1). The variations in $\mathrm{CHL}_{1}$ and $\mathrm{N}_{1}$ field measurements of different crop types and landscapes are then presented (Sect. 4.2), and the observed within-canopy 
Table 1. Overview of SPOT satellite data including sensor and atmospheric data estimated from MODIS and AIRS satellite data. Atmospheric data include aerosol optical depth $(\tau)$, ozone content $\left(\mathrm{O}_{3}\right)$ and total precipitable water content (TPW). Spatial resolutions $(\Delta x)$ of the SPOT images are also shown.

\begin{tabular}{|c|c|c|c|c|c|c|c|c|c|c|c|c|c|c|}
\hline Country & $\begin{array}{r}\text { Site } \\
\text { acronym }\end{array}$ & $\begin{array}{r}\text { Latitude } \\
\left({ }^{\circ} \mathrm{N}\right)\end{array}$ & $\begin{array}{r}\text { Longitude } \\
\left({ }^{\circ} \mathrm{E}\right)\end{array}$ & $\begin{array}{c}\text { Elevation } \\
\text { (m a.s.1.) }\end{array}$ & $\begin{array}{r}\text { SPOT } \\
\text { Date }\end{array}$ & $\begin{array}{r}\text { SPOT } \\
\text { Time } \\
(h)\end{array}$ & $\begin{array}{r}\text { SPOT } \\
\text { Satellite }\end{array}$ & $\begin{array}{l}\text { SPOT } \\
\text { Sensor }\end{array}$ & $\begin{array}{r}\text { SPOT } \\
\Delta x \\
(\mathrm{~m})\end{array}$ & $\begin{array}{r}\text { MODIS } \\
\text { Time } \\
(h)\end{array}$ & $\begin{array}{r}\text { MODIS } \\
\tau \\
(-)\end{array}$ & $\begin{array}{r}\text { AIRS } \\
\text { Time } \\
(h)\end{array}$ & $\begin{array}{r}\text { AIRS } \\
\mathrm{O}_{3} \\
\text { (Dobson) }\end{array}$ & $\begin{array}{r}\text { AIRS } \\
\text { TPW } \\
\left(\mathrm{kg} \mathrm{m}^{-2}\right)\end{array}$ \\
\hline Denmark & DK08 & 56.34 & 9.66 & 60 & 31 May 08 & 10.50 & SPOT-4 & HRVIR1 & 20 & 11.10 & 0.234 & 11.25 & 322.8 & 18.82 \\
\hline Poland & PL & 52.04 & 16.78 & 80 & 01 Jun 08 & 10.20 & SPOT-4 & HRG1 & 10 & 10.20 & 0.177 & 12.06 & 353.4 & 15.43 \\
\hline Netherlands & NL & 53.14 & 6.13 & 2 & 09 Jun 08 & 10.46 & SPOT-5 & HRG2 & 10 & 11.05 & 0.091 & 11.19 & 327.9 & 22.95 \\
\hline Italy & IT & 40.51 & 14.94 & 15 & 27 Jun 08 & 10.03 & SPOT-5 & HRG1 & 10 & 9.20 & 0.459 & 11.30 & 340.6 & 27.20 \\
\hline Scotland & UK & 55.78 & -3.24 & 280 & $21 \mathrm{Jul} 08$ & 11.09 & SPOT-4 & HRVIR1 & 20 & 11.55 & 0.021 & 11.55 & 330.0 & 15.00 \\
\hline Denmark & DK09 & 56.35 & 9.66 & 60 & 17 Apr 09 & 10.45 & SPOT-5 & HRG1 & 10 & 11.55 & 0.053 & 12.11 & 385.5 & 10.36 \\
\hline
\end{tabular}

variations in $\mathrm{CHL}_{1}$ are categorized (Sect. 4.3). The capability of REGFLEC to quantify LAI, $\mathrm{CHL}_{1}$ and $\mathrm{N}_{1}$ over a large range of environmental conditions in Europe is evaluated in Sects. 4.4 and 4.5, and the distribution and size of vegetation $\mathrm{N}$ pools in the five European agricultural landscapes are finally assessed and discussed in Sect. 4.5. Section 5 discusses the capability of remote sensing data to assess LAI, $\mathrm{CHL}_{1}$ and $\mathrm{N}_{1}$ (Sect. 5.1), and the contribution of remote sensing to assess landscape-scale variation in carbon-nitrogen dynamics (Sect. 5.2).

\section{Landscape sites}

In 2006, arable land for crop production covered $25 \%$ of the European land area, and grassland pastures covered an additional $17 \%$, which add up to a total European agricultural land area of $2286931 \mathrm{~km}^{2}$ (EEA/ETC-LUSI, 2010). The five study areas each represent regions of $10 \mathrm{~km} \times 10 \mathrm{~km}$ and are centered on the NitroEurope landscapes. They are geographically located across a European south-north gradient, ranging from $40^{\circ} 30^{\prime} \mathrm{N}$ to $56^{\circ} 20^{\prime} \mathrm{N}$ and a west-east gradient from $3^{\circ} 14^{\prime} \mathrm{W}$ to $16^{\circ} 46^{\prime} \mathrm{E}$ (Fig. 1), thereby representing 3 European climate zones: temperate/humid continental (Denmark and Poland), temperate oceanic (the Netherlands and the United Kingdom), and warm Mediterranean (Italy) (Peel et al., 2007). The climate zones reflect the agricultural land use patterns of the selected landscape sites, which are dominated by grassland in the Netherlands (NL) and Scotland (UK), grain crops, maize and potatoes in Denmark (DK) and Poland (PL), and maize, vegetables and fruit production in Italy (IT).

At the UK site, agricultural land use comprises upland pasture (38\%) and crop fields (10\%) which are intermixed with peat bogs $(38 \%)$, semi-natural grassland, heathland and moorland $(22 \%)$ and some woodland (14\%). Agricultural production is dominated by sheep, beef and poultry systems, although the latter does not contribute substantially to agricultural land use and cropping patterns in the landscape, being dependent on feeds brought in from outside the area. The landscape is located in an upland area (280 m a.s.1.), and the prevailing soil types are Dystric Cambisols, Dystric His- tosols and Dystric Gleysols (ESDB, 2010), which are indicative of acidic soils.

The Dutch lowland site (NL) is located just $2 \mathrm{~m}$ above sea level and dominated by cultivated grassland and pasture (79\%). Only a few crop fields (maize) were observed. There is no woodland in the study area, but many tree belts. Urban/suburban land use covers $17 \%$, and $4 \%$ of the area is taken up by water bodies and inland marshes..

At the DK site, land use is dominated by croplands (70\%) intermixed with woodland $(21 \%)$ and urban/suburban areas $(6 \%)$. The dominant crop type in this region is wheat, but winter oilseed rape, barley and maize are also common. The area is a lowland area $(60 \mathrm{~m}$ a.s.1.), with fertile soils composed by Haplic Podzols and Gleyic Luvisols (ESDB, 2010).

At the Polish site, $76 \%$ of the land area is cultivated by crops, $8 \%$ by grassland, and woodland covers $13 \%$ of the study landscape. Crop fields are generally very small and managed as small family farms, but large fields are observed in the few but large former cooperative farms. The area is located $80 \mathrm{~m}$ a.s.l., and soils are classified as Gleyic Luvisols and Gleyic Fluvisols (ESDB, 2010), indicating exposure to intermittent waterlogging.

At the Italian site, agricultural production is dominated by horticulture and dairy buffalo farming. Approximately $90 \%$ of the area is used for cultivation, with $12 \%$ having a complex cultivation pattern. Cultivated areas include vineyards, fruit trees, maize and vegetables. Vegetable fields are rowcropped with up to $1-2 \mathrm{~m}$ between rows, and many plastic greenhouses and bare soil fields were observed in the area during the July measurement campaign. The area is located $15 \mathrm{~m}$ a.s.l., and the dominant soil type is Eutric Cambisol (ESDB, 2010).

\section{Materials and methods}

\subsection{Satellite data}

Multi-spectral high spatial resolution satellite image data representing radiance in the green $(0.5-0.59 \mu \mathrm{m})$, red $(0.61-$ $0.68 \mu \mathrm{m})$ and NIR $(0.79-0.89 \mu \mathrm{m})$ spectra, as measured by the HRG (high resolution geometry) and HRVIR (high 

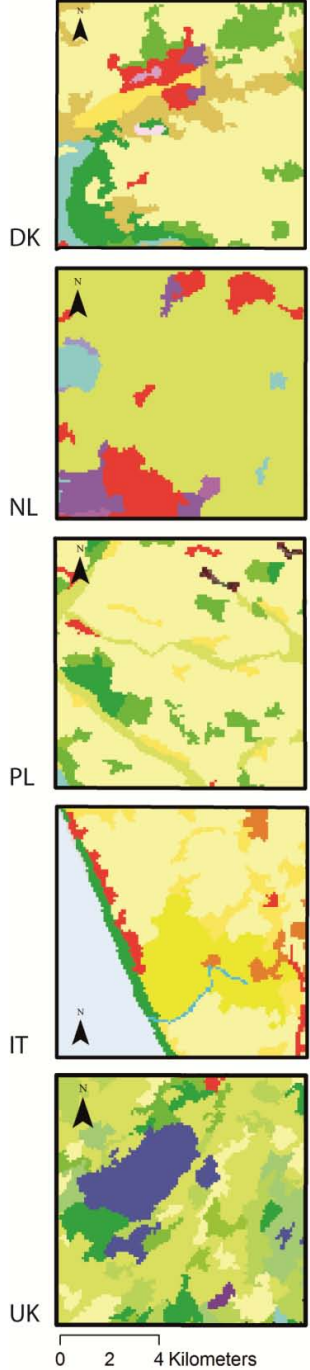
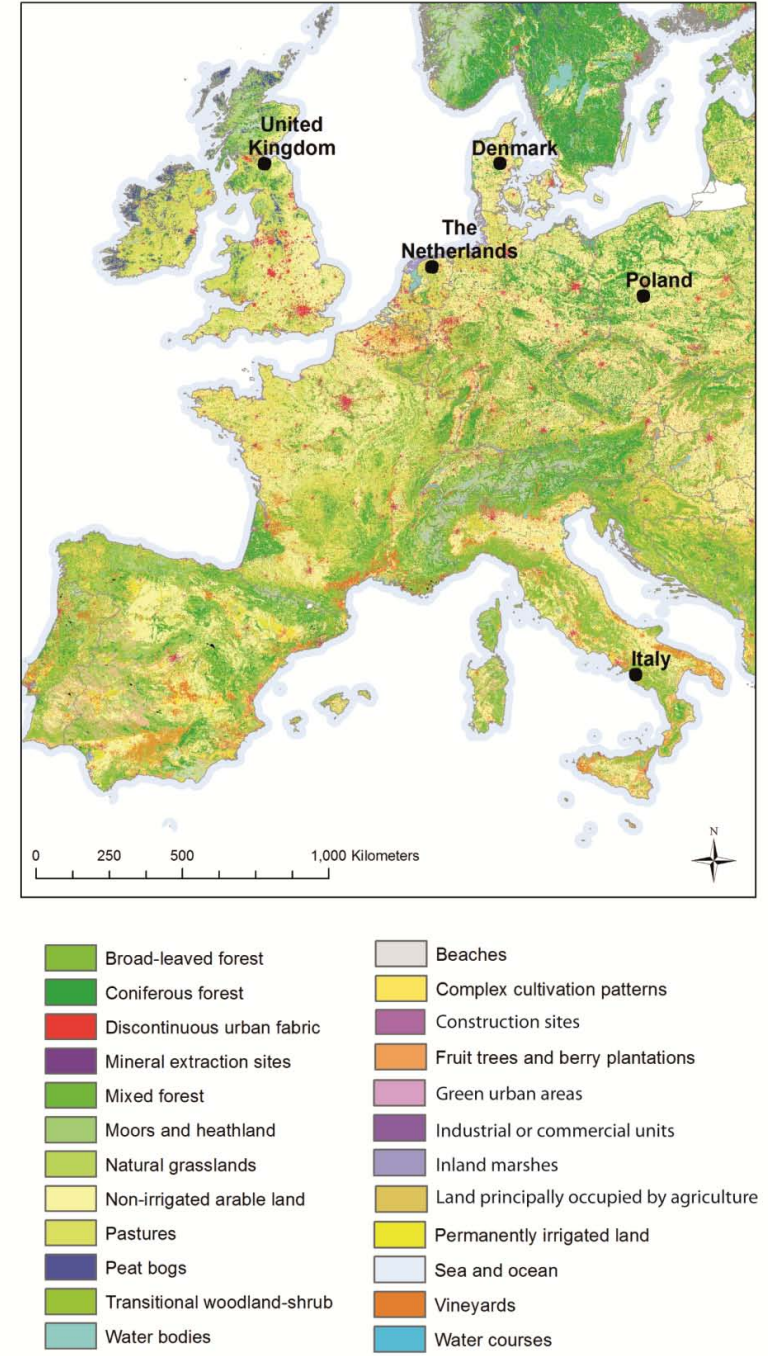

Fig. 1. Land cover and locations of five European landscape sites. Courtesy: CORINE land cover (CLC2000), European Environment Agency (http://www.eea.europa.eu/legal/copyright).

resolution visible and infra-red) sensors aboard the SPOT-4 and SPOT-5 satellites were acquired within the NitroEurope project and used in this study (Table 1). The acquired satellite data were processed to Level $2 \mathrm{~A}$ which includes standard geometric corrections. The georeferencing quality was assessed by overlaying the satellite images by ESRI's Streetmap Premium Europe Tele Atlas data set, and minor deviations were adjusted by shifting the image coordinates in the $X-Y$ directions. One satellite image is available for each landscape for the period 31 May-21 July 2008, and one additional satellite image is available for the DK site during an intensive measurement campaign for 19 April 2009. Image data are available at a $10 \mathrm{~m}$ spatial resolution for most sites, except for the UK and the Danish site in 2008 (DK08), where images are available with $20 \mathrm{~m}$ resolution. All satellite images were atmospherically corrected using data on aerosol optical depth, ozone and atmospheric precipitable water content from the
MODIS and AIRS/AMSU sensors aboard the Terra (EOS AM) and Aqua (EOS PM) satellites. Atmospheric data were acquired as close as possible in time to the acquisition of the SPOT data (Table 1). Surface reflectance is calculated considering directional multiple scattering using the 6SV1 atmospheric radiative transfer model (Kotchenova et al., 2006), which is included in the REGFLEC tool. REGFLEC results and SVIs were extracted for $3 \times 3$ pixels centered at each field plot for comparison with field measurements.

\subsection{Field data}

In each study landscape, field measurements of LAI and SPAD meter indices (related to $\mathrm{CHL}_{1}$ and $\mathrm{N}_{1}$ ) or $\mathrm{N}_{1}$ were made in 7-22 fields over 1-2 days within 4-10 days of the relevant satellite image acquisitions, to provide field reference data for evaluating the REGFLEC simulations. Field 

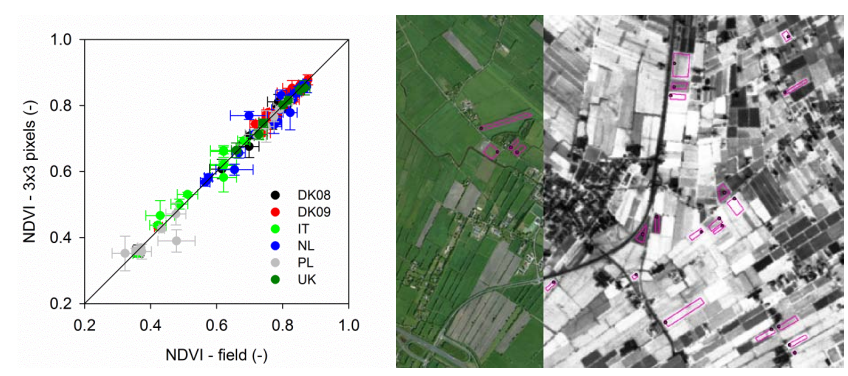

Fig. 2. Comparison of remote-sensing-based calculations of a SVI (the Normalized Difference Vegetation Index, NDVI) averaged for $3 \times 3$ pixels centred at field plots and averaged for the the complete fields in each of the landscapes. The ArcMap function Swipe was used to drag the remote sensing NDVI image layer back and forth over an aerial image to support the manual digitization of fields, as illustrated in the figure. The aerial image is seen with natural colours, and the grey-scale image represents NDVI calculated from SPOT image data with $10 \mathrm{~m}$ spatial resolution. Aerial images of each landscape were available as base maps in ArcMap (Source: ESRI, DigitalGlobe, GeoEye, i-cubed, USDA, USGS, AEX, Getmapping, Aerogrid, IGN, IGP and the GIS User Community).

measurements were conducted in a total of 93 homogeneous field plots (Table 2) within the five landscapes. Each field plot is represented by two sub-areas of each $3 \mathrm{~m} \times 3 \mathrm{~m}$ located within a $10 \mathrm{~m} \times 10 \mathrm{~m}$ region. Field plots were geographically referenced with an accuracy of $0.5 \mathrm{~m}$ using GPS (Trimble Geo XT, Trimble, USA). Plots were generally located in different fields, however, at the Italian site five plots were located within a large experimental maize field exposed to different stress treatments. The homogeneity of experimental fields were verified by comparing remote sensing data of field plots $(3 \times 3$ pixels $)$ with the corresponding remote sensing data for the complete fields which were digitized for this purpose (Fig. 2).

\subsubsection{LAI}

LAI was measured with the LAI-2000 instrument (LAI2000, LiCor, USA) which uses canopy transmission data measured along a transect. Despite being an indirect estimate of LAI, measurements from the LAI-2000 instrument were shown to be in very good agreement with destructively sampled LAI of maize, wheat and barley until the senescent phase sets in (eg. Boegh et al., 2004). In this study, measurements were conducted in the beginning or middle of the growing season (Table 1) where LAI estimation uncertainty is low. Using data published in Boegh et al. (2004), the LAI2000 instrument explained $96 \%$ of direct LAI estimates in the vegetative period, and the LAI-2000 estimation uncertainty, assessed as the relative standard error, was found to be $21 \%$. LAI was measured in two neighbouring plots of each field (Sect. 3.2), with each LAI estimate being based on
Table 2. Number of field plots and vegetation types represented by field measurements in the landscape sites.

\begin{tabular}{lll}
\hline Site & $\mathrm{n}$ & Vegetation types \\
\hline DK08 & 20 & winter wheat, barley, maize \\
DK09 & 22 & winter wheat, winter rape \\
NL & 22 & grass, maize \\
PL & 13 & maize, barley, alfalfa, potatoes, \\
& & rye, oilseed rape \\
IT & 9 & maize, tomato, artichoke, alfalfa \\
UK & 7 & grass, wheat \\
all & 93 & \\
\hline
\end{tabular}

four light transmission measurements along a $3 \mathrm{~m}$ transect. If the LAI estimates of the two transects varied, a third transect (a third plot) was included. In a few cases at the grassland sites in NL, up to four transects were included due to high spatial data variability. In all fields, the average LAI is used to represent the field plot. In the UK landscape, LAI was estimated using light transmission measurements along a $10 \mathrm{~m}$ transect. Based on the 2-4 sets of LAI estimates in each field, the averaged relative uncertainty ( $\mathrm{sd} / \mathrm{mean}$ ) is found to be $\approx 10 \%$, except for the UK grassland plots where LAI is very low $(\approx 1)$ and the relative uncertainty is higher (median $34.9 \%$ ). In Denmark, UK, the Netherlands, Poland and Italy, the averaged uncertainties for LAI measurements are 7.8, 37.7, 13.4, 10.7 and $11.5 \%$, respectively. Considering also LAI-2000 estimation uncertainty, the combined instrument and measurement uncertainties for LAI-2000 data are in the range $22-25 \%$.

\subsubsection{Chlorophyll and nitrogen}

At the UK site, plant sampling was undertaken in the middle $2 \mathrm{~m}$ of the $10 \mathrm{~m}$ transect within a $50 \mathrm{~cm} \times 50 \mathrm{~cm}$ square. Both green leaves and full plants were sampled. For each, a total $\mathrm{C}$ and $\mathrm{N}$ analysis was carried out after weighing and drying, and vegetation $\mathrm{N}$ and dry biomass were measured. For conversion to area-based $\mathrm{N}_{1}$ of the natural grasses, a leaf specific weight of $40 \mathrm{~g} \mathrm{~m}^{-2}$ was used. In the four other landscapes, non-destructive measurements of $\mathrm{CHL}_{1}$ and $\mathrm{N}_{1}$ were made using hand-held, non-destructive SPAD meter measurements. The SPAD meter (SPAD 502-DL, Minolta, USA) emits and measures leaf transmittance in the red (0.6$0.7 \mu \mathrm{m})$ and NIR $(0.86-1.06 \mu \mathrm{m})$ spectra and provides a ratio that is closely correlated with $\mathrm{CHL}_{1}$ and $\mathrm{N}_{1}$ (Wang et al., 2004). In order to convert the SPAD index to $\mathrm{CHL}_{1}$ and $\mathrm{N}_{1}$ contents, calibration was conducted on sampled leaves for maize, wheat, barley, oilseed rape, grasses, tomatoes, artichokes and alfalfa. For SPAD meter calibration of tomatoes, artichokes and alfalfa, 10-15 SPAD indices were measured for leaves of different "greenness", with the samples subsequently analysed in the laboratory for $\mathrm{CHL}_{1}$ and $\mathrm{N}_{1}$. For SPAD meter calibration of wheat, barley, grass, maize and 
oilseed rape, SPAD indices were thoroughly measured in the laboratory and leaves cut into small $(1-2 \mathrm{~cm})$ pieces for similar SPAD values. Leaf pieces were divided into pools of similar SPAD index ranges (ie. 6-10, 11-15, .., 66-70), and each pool was further split into two samples for $\mathrm{CHL}_{1}$ and $\mathrm{N}_{1}$ estimation, respectively. The samples for $\mathrm{CHL}_{1}$ analysis were kept frozen until analysis, while the samples for $\mathrm{N}_{1}$ estimation were oven dried at $80^{\circ}$ for $24 \mathrm{~h}$. Chlorophyll $(\mathrm{a}+\mathrm{b})$ content was extracted using ethanol and extinction coefficients published by Lichtenthaler (1987). Nitrogen was estimated using a CHNS-O Elemental Analyzer (CE Instruments, UK). Leaf areas were measured using a scanner (EPSON Expression 1680 Professional, Seiko Epson Corporation, US), and specific weights estimated for the same leaf samples were used to convert the mass-based chlorophyll and leaf $\mathrm{N}$ concentrations to leaf area based $\mathrm{CHL}_{1}$ and $\mathrm{N}_{1}$. $\mathrm{CHL}_{1}$ was found to be exponentially related to SPAD values $\left(r^{2}=0.73-0.93\right)$, as also shown in other studies, while $\mathrm{N}_{1}$ was linearly related to the SPAD indices $\left(r^{2}=0.62-0.89\right)$. Due to the close similarity of SPAD-CHL 1 calibration curves for all vegetation types (Fig. 3a), it was decided to use one single calibration curve for all crops. The resulting calibration curve fit all data quite well $\left(r^{2}=0.87\right)$, including the few data that were available for artichokes, tomatoes and alfalfa, however the standard error of estimates is quite high $(23.7 \%)$ compared to some other studies where a SPAD meter was applied for species-specific $\mathrm{CHL}_{1}$ estimation (e.g. Markwell et al., 1995; and Houborg and Anderson, 2009). Excellent agreement was however found when comparing the calibration curve established for this study with that of the same SPAD meter in an independent study (Houborg and Boegh, 2008). This strongly indicates that one single SPAD- $\mathrm{CHL}_{1}$ calibration curve can be used for leaf area-based estimation of chlorophyll over a large range of crop types, even when being at different development stages. Uddling et al. (2007) also found that SPAD$\mathrm{CHL}_{1}$ calibration curves collapsed for wheat and birch leaves when data were expressed on a leaf area basis, but that this was not the case for potato which has thicker leaves. In the current study, the range of leaf specific weights is quite narrow $\left(52-58 \mathrm{~g} \mathrm{~m}^{-2}\right)$.

For $\mathrm{N}_{1}$, species-specific SPAD meter calibration curves are needed (Fig. 3b). Based on the data shown in Fig. 3b, the relative standard error of $\mathrm{N}_{1}$ estimates is $12.9 \%$. The better estimates for $\mathrm{N}_{1}$ than $\mathrm{CHL}_{1}$ may be due to the larger samples for $\mathrm{N}_{1}$ estimation (69) than for $\mathrm{CHL}_{1}$ estimation (30) and the use of species-specific SPAD- $\mathrm{N}_{1}$ calibration curves. Combining the SPAD-CHL $\mathrm{CH}_{1}$ and SPAD- $\mathrm{N}_{1}$ calibration curves, the species-specific nitrogen partitioning is clearly illustrated (Fig. 3c). The $\mathrm{CHL}_{1}-\mathrm{N}_{1}$ relationships (Fig. 3c) were used to convert REGFLEC CHL $\mathrm{CH}_{1}$ simulations to $\mathrm{N}_{1}$.

In each field plot, 30-70 SPAD meter measurements were conducted depending on the variability of the data. In order to assess the possible impact of vertical $\mathrm{CHL}_{1}$ variability on the total chlorophyll content of the canopy, measurements were conducted on green leaves at five heights in the canopy
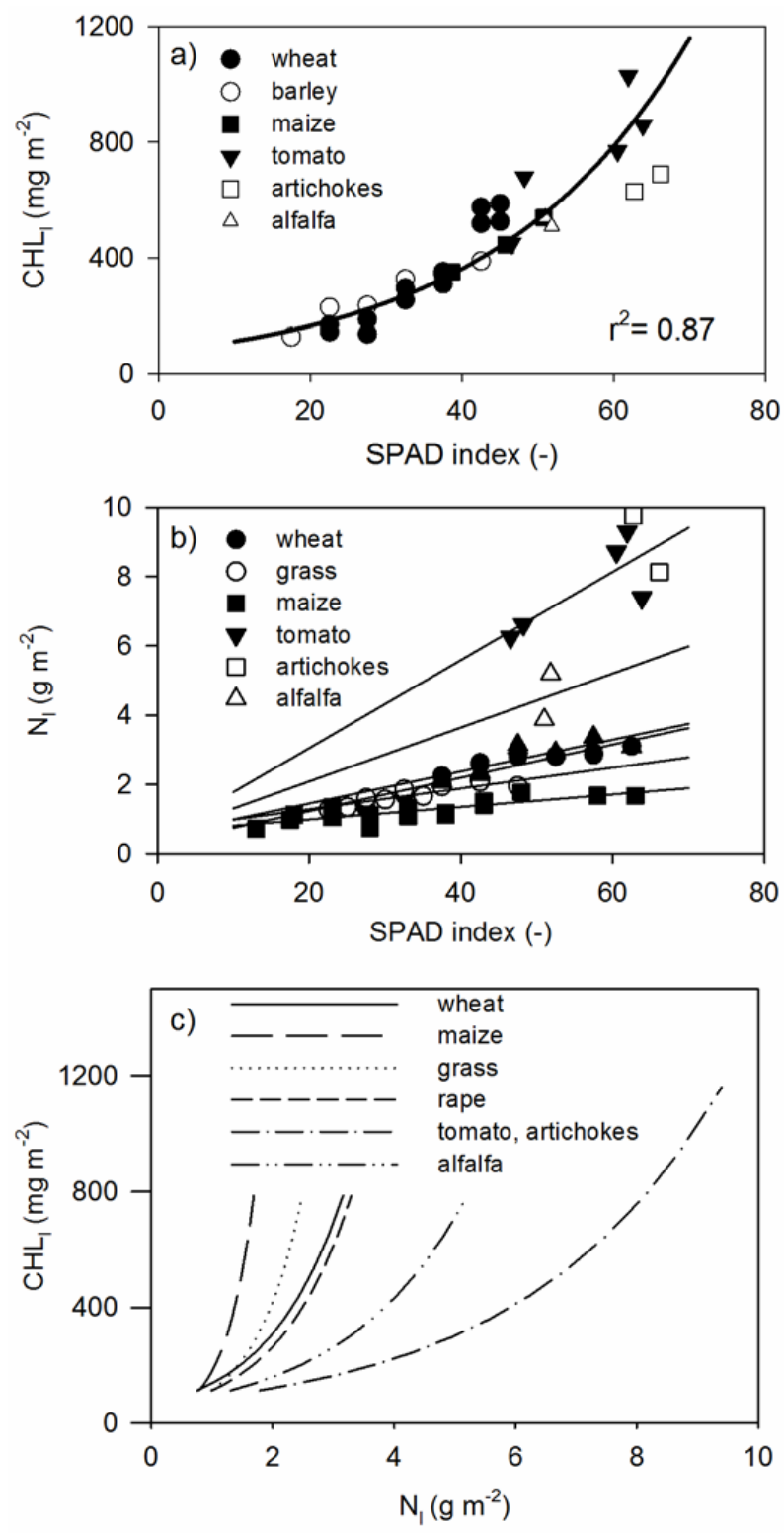

Fig. 3. SPAD meter calibration curves for (a) leaf chlorophyll $\left(\mathrm{CHL}_{1}\right)$ and (b) leaf nitrogen density $\left(\mathrm{N}_{1}\right)$, and (c) empirical relationships between $\mathrm{N}_{1}$ and $\mathrm{CHL}_{1}$ derived by combining SPAD calibration equations for $\mathrm{CHL}_{1}$ and $\mathrm{N}_{1}$.

(this was not always possible for the NL grass fields, due to low canopy heights and narrow leaves). At each level, two measurements were conducted on the same leaf to identify deviating data caused by erroneous data resulting from measurement on veins or, for small grass leaves, insufficient leaf cover of the sensor. If one of the paired measurements approached zero, and the other did not, the lower measurement was discarded.

Canopy chlorophyll $\left(\mathrm{CHL}_{\mathrm{c}}\right)$ and canopy nitrogen $\left(\mathrm{N}_{\mathrm{c}}\right)$ contents are computed by multiplication of LAI and the 
averaged leaf-scale measurements, ie.

$\mathrm{CHL}_{\mathrm{c}}=L A I \times \overline{\mathrm{CHL}_{\mathrm{l}}}$,

$\mathrm{N}_{\mathrm{c}}=L A I \times \overline{\mathrm{N}_{\mathrm{l}}}$,

where $\overline{\mathrm{CHL}_{1}}$ is the average $\mathrm{CHL}_{1}$ measured at five height levels in the canopy, and $\bar{N}_{1}$ is the corresponding average $\mathrm{N}_{1}$. Since the variation in $\mathrm{CHL}_{1}$ and $\mathrm{N}_{1}$ with height is not all due to measurement uncertainty, but related to vertical data structure, relative measurement uncertainties $\left(\Delta_{1}\right)$ for $\overline{\mathrm{CHL}_{1}}$ and $\overline{\mathrm{N}_{1}}$ are calculated by propagating absolute data uncertainty $(\sigma)$ at each measurement level:

$\Delta_{1}=\frac{1}{5} \sqrt{\left(\sigma_{(0.2)}^{2}+\sigma_{(0.4)}^{2}+\sigma_{(0.6)}^{2}+\sigma_{(0.8)}^{2}+\sigma_{(1.0)}^{2}\right)} / \bar{x}_{1}$,

where $\sigma_{(h r)}$ is the standard deviation of leaf-scale measurements $\left(\mathrm{CHL}_{1}\right.$ or $\left.\mathrm{N}_{1}\right)$ at the relative heights (hr) 0.2, 0.4, 0.6, 0.8 and 1.0, and $\bar{x}_{1}$ represents $\overline{\mathrm{CHL}_{1}}$ or $\overline{\mathrm{N}}_{1}$. The relative total uncertainties for the bulk canopy estimates $\left(\Delta_{c}\right)$ of $\mathrm{CHL}_{\mathrm{c}}$ and $\mathrm{N}_{\mathrm{c}}$ are given by

$\Delta_{\mathrm{c}}=\sqrt{\Delta_{1}^{2}+\Delta_{\mathrm{SPAD}}^{2}+\Delta_{\mathrm{LAI}}^{2}+\Delta_{\mathrm{LAI}-2000}^{2}}$

where $\Delta_{\text {SPAD }}$ is the calibration uncertainty of the SPAD meter (Fig. 3), $\Delta_{\text {LAI }}$ is the measurement uncertainty of LAI, and $\Delta_{\text {LAI-2000 }}$ is the LAI-2000 instrument uncertainty (Sect. 3.2.1). Overall, average measurement uncertainties for $\overline{\mathrm{CHL}_{1}}$ are 12, 9, 9, 24 and $11 \%$ for the landscapes DK08, DK09, IT, NL and PL respectively, and for $\overline{\mathrm{N}_{1}}$ the average measurement uncertainties are $8,5,4,10$ and $7 \%$ respectively. This propagates to total (averaged) uncertainties of $29-47 \%$ for $\mathrm{CHL}_{\mathrm{c}}$, and to total (averaged) uncertainties of $25-32 \%$ for $\mathrm{N}_{\mathrm{c}}$ of the five landscapes. Uncertainty of $\mathrm{N}_{1}$ data in UK are not known, but are set similar to the LAI uncertainty of UK plots (average $38 \%$ ). It should be noted that vertical profile measurements were not conducted for grasses in NL, and that in-canopy CHL structure may explain the higher measurement uncertainties calculated for $\overline{\mathrm{CHL}_{1}}$ and $\overline{\mathrm{N}_{1}}$ estimates at this site.

\subsection{Spectral vegetation indices}

Five different SVIs were calculated from each of the six satellite images in order to assess field data consistency and evaluate REGFLEC performance. The Simplified Ratio (SR) and the Normalized Difference Vegetation index (NDVI) were the earliest SVIs to be developed, and are frequently used indices. They are calculated as

$\mathrm{SR}=\rho_{\mathrm{NIR}} / \rho_{\mathrm{red}}$,

$\mathrm{NDVI}=\left(\rho_{\mathrm{NIR}}-\rho_{\mathrm{red}}\right) /\left(\rho_{\mathrm{NIR}}+\rho_{\mathrm{red}}\right)$, where $\rho$ is spectral surface reflectance. Despite inherent normalization of NDVI to reduce soil background and atmospheric sensitivity of SR, the NDVI remains sensitive to soil reflectance. A soil-adjusted vegetation index (SAVI) was developed, which uses a soil-adjustment factor to shift the origin of the NIR-red spectral space and accounts for first-order soil-vegetation interactions and differential NIR and red radiative transfer through a canopy (Huete, 1988). The Enhanced Vegetation Index (EVI) is derived from SAVI and includes a blue spectral band to reduce sensitivity to atmospheric aerosol contents (Huete et al., 2002). EVI was found to have a good correlation with LAI of agricultural fields (Boegh et al., 2002). Both the NDVI and the EVI are available from the MODIS satellite sensors as global 8 day products at a $1 \mathrm{~km}$ resolution. Because many satellites, including the SPOT satellites, do not measure radiance in the blue band, a two-band EVI index (EVI2, Jiang et al., 2008) was developed, which is closely related to EVI. The EVI2 is calculated as

$\mathrm{EVI} 2=2\left(\rho_{\mathrm{NIR}}-\rho_{\mathrm{red}}\right) /\left(\rho_{\mathrm{NIR}}+\rho r_{\mathrm{ed}}+1\right)$.

Since the strong absorption of red light by the bulk chlorophyll content of dense canopies can cause data saturation in the peak (red) absorption band of chlorophyll, the far-red or green reflectance was found to be more sensitive to canopyscale chlorophyll variations than $\rho_{\text {red }}$ (Yoder and Waring, 1994; Gitelson et al., 1996). This led to the proposal of a Green NDVI which uses a green reflectance $\left(\rho_{\text {green }}\right)$ instead of $\rho_{\text {red }}$ and was closely related to $\mathrm{CHL}_{1}$ (Gitelson et al., 1996):

GNDVI $=\left(\rho_{\text {NIR }}-\rho_{\text {green }}\right) /\left(\rho_{\text {NIR }}+\rho_{\text {green }}\right)$.

A related measure, the green Chlorophyll Index (CI) was proposed to estimate the total canopy chlorophyll content (e.g. Gitelson et al., 2005):

$\mathrm{CI}=\rho_{\mathrm{NIR}} / \rho_{\text {green }}-1$.

Many other SVIs for $\mathrm{CHL}_{1}$ or $\mathrm{N}_{1}$ estimation combine three or more narrowband reflectance data in the the red-NIR transition zone of vegetation reflectance (the "red-edge" region), such as the MERIS Terrestrial Chlorophyll Index (MTCI) (Dash et al., 2010). However, such data are not yet available with the spatial resolution and coverage required for the current study.

\subsection{The REGFLEC model}

REGFLEC (www.regflec.com) is an automatic imagebased methodology for regional $\mathrm{CHL}_{1}$ and LAI mapping. REGFLEC version 1.0 (Houborg and Anderson, 2009) is used here, which requires multi-spectral data measured in green, red and NIR bands. REGFLEC combines the atmospheric radiative transfer model 6SV1 (Kotchenova et al., 2006; Vermote et al., 1997), the canopy radiative transfer 
Table 3. Means and standard deviations (sd) of SPOT NDVI for the crop- and grasslands, measured LAI, leaf chlorophyll density (CHL ( $_{1}$, leaf nitrogen density $\left(\mathrm{N}_{1}\right)$, canopy chlorophyll density $\left(\mathrm{CHL}_{\mathrm{c}}\right)$ and canopy nitrogen density $\left(\mathrm{N}_{\mathrm{c}}\right)$ within the European landscape sites. Standard deviations of leaf-scale measurements are shown to represent variability between field canopies (sd1) and the mean variability within field canopies (sd2). * Tomato fields not included.

\begin{tabular}{|c|c|c|c|c|c|c|c|c|c|c|c|c|c|c|}
\hline $\begin{array}{l}\text { mean } \\
(-)\end{array}$ & $\begin{array}{r}\text { NDVI } \\
\text { sd } \\
(-)\end{array}$ & $\begin{array}{r}\text { NDVI } \\
\text { mean } \\
(-)\end{array}$ & $\begin{array}{r}\text { LAI } \\
\text { sd } \\
(-)\end{array}$ & $\begin{array}{r}\text { LAI } \\
\left(\mathrm{mg} \mathrm{m}^{-2}\right)\end{array}$ & $\begin{array}{r}\mathrm{CHL}_{1} \\
\text { mean } \\
\left(\mathrm{mg} \mathrm{m}^{-2}\right)\end{array}$ & $\begin{array}{r}\mathrm{CHL}_{\mathrm{l}} \\
\mathrm{sd} 1 \\
\left(\mathrm{mg} \mathrm{m}^{-2}\right)\end{array}$ & $\begin{array}{r}\mathrm{CHL}_{\mathrm{l}} \\
\mathrm{sd} 2 \\
\left(\mathrm{~g} \mathrm{~m}^{-2}\right)\end{array}$ & $\begin{array}{r}\mathrm{N}_{\mathrm{l}} \\
\text { mean } \\
\left(\mathrm{g} \mathrm{m}^{-2}\right)\end{array}$ & $\begin{array}{r}\mathrm{N}_{\mathrm{l}} \\
\mathrm{sd} 1 \\
\left(\mathrm{~g} \mathrm{~m}^{-2}\right)\end{array}$ & $\begin{array}{r}\mathrm{N}_{1} \\
\mathrm{sd} 2 \\
\left(\mathrm{mg} \mathrm{m}^{-2}\right)\end{array}$ & $\begin{array}{r}\mathrm{CHL}_{\mathrm{c}} \\
\text { mean } \\
\left(\mathrm{mg} \mathrm{m}^{-2}\right)\end{array}$ & $\begin{array}{r}\mathrm{CHL}_{\mathrm{c}} \\
\mathrm{sd} 1 \\
\left(\mathrm{~g} \mathrm{~m}^{-2}\right)\end{array}$ & $\begin{array}{r}\mathrm{N}_{\mathrm{c}} \\
\text { mean } \\
\left(\mathrm{g} \mathrm{m}^{-2}\right)\end{array}$ & $\begin{array}{r}\mathrm{N}_{\mathrm{c}} \\
\mathrm{sd} 1\end{array}$ \\
\hline DK08 & 0.73 & 0.34 & 2.9 & 1.4 & 391 & 78 & 105 & 2.13 & 0.33 & 0.47 & 1095 & 588 & 6.10 & 3.24 \\
\hline DK09 & 0.72 & 0.39 & 2.2 & 1.1 & 434 & 96 & 164 & 2.27 & 0.19 & 0.24 & 1041 & 733 & 4.97 & 2.37 \\
\hline NL & 0.73 & 0.34 & 3.0 & 1.5 & 350 & 121 & 121 & 1.71 & 0.23 & 0.22 & 1037 & 698 & 5.12 & 3.15 \\
\hline PL & 0.67 & 0.42 & 2.1 & 1.1 & 402 & 102 & 67 & 2.27 & 0.97 & 0.35 & 832 & 633 & 5.10 & 5.36 \\
\hline IT & 0.49 & 0.42 & $2.0 *$ & $0.7^{*}$ & 647 & 151 & 131 & 4.20 & 2.87 & 0.45 & $1370^{*}$ & $498^{*}$ & $5.51^{*}$ & $2.92^{*}$ \\
\hline UK & 0.74 & 0.3 & 1.8 & 1.9 & - & - & - & 1.11 & 0.44 & - & - & - & 2.52 & 3.38 \\
\hline
\end{tabular}

model ACRM (Kuusk, 2001) and the leaf optical properties model PROSPECT (Baret and Fourty, 1997; Jacquemoud and Baret, 1990) to predict $\mathrm{CHL}_{1}$ and LAI directly from atsensor radiance data measured in three spectral bands (green, red and NIR). The models used by REGFLEC are based on physical laws that describe the transfer and interaction of spectral radiation within the atmospheric column and canopy to provide a connection between the radiance signal measured at the satellite sensor and the biophysical properties of the canopy which are responsible for the surface reflectance. In this process, the observed satellite reflectance observations are matched with the simulated spectral reflectance to identify the combination of soil and vegetation variables providing the best reflectance fit (Houborg and Anderson, 2009). The strength of the REGFLEC tool is that it is independent of field data for model calibration, and it estimates automatically the vegetation- and soil-specific parameters for mapped soil and vegetation types in the area, which helps to constrain the inversion process and improve the estimation accuracy of biophysical parameters (Houborg and Anderson, 2009). For this purpose, REGFLEC requires as inputs (a) a land use map that defines classes of uniform canopy characteristics (i.e. leaf structure, Markov clumping parameter, leaf inclination angle, brown pigment concentration of senescent leaf material) which is needed to constrain the retrieval of LAI and $\mathrm{CHL}_{1}$ and (b) a soil map to assist the regional extrapolation of soil background reflectance (the acquisition of land use and soil maps is described in the end of this section). Furthermore, atmospheric state data and solar and sensor view angle geometries must be specified. Following atmospheric correction of satellite data (using the 6SV1 model), the ACRM-PROSPECT model is first run in forward mode to build lookup tables representing relationships between spectral reflectance, $\mathrm{CHL}_{1}$ and LAI. This includes model generated curves of LAI as a function of $\rho_{\text {NIR }}$, NDVI and GNDVI, in addition to curves of $\mathrm{CHL}_{1}$ as a function of $\rho_{\text {green }}$. The lookup tables (LUTs) are built using a wide parameter space representative of a full range of soil and vegetation parameters (Houborg and Anderson, 2009). REGFLEC then identifies bare soil pixels or low vegetation pixels $(\mathrm{LAI}<0.5)$ and estimates a single soil reflectance parameter for each of these by running the model in LUT-based inverse mode for a limited number of averaged spectral reflectance values representing each soil class. For the sparsely vegetated pixels (LAI < 0.5), a mismatch in LAI estimated using observations of $\rho_{\text {NIR }}\left(\mathrm{LAI}-\rho_{\mathrm{NIR}}\right)$, NDVI (LAI-NDVI) and GNDVI (LAIGNDVI) is most likely due to soil reflectance errors. Consequently, the soil reflectance value which is providing the best fit between the three independent LAI estimates is retained and used to assign representative estimates for each mapped soil type. Next, ACRM-PROSPECT is run in inverse mode for high NDVI pixels of each land use class in order to estimate four class-specific vegetation parameters (leaf structure, leaf angle distribution, fraction of senescent leaves and Markov clumping parameter). Following model parameterization of class-specific soil and vegetation characteristics, ACRM-PROSPECT is finally run in forward mode for pixel-wise mapping of $\mathrm{LAI}$ and $\mathrm{CHL}_{1}$ using appropriate REGFLEC established predictive spectral reflectance relationships (LUTs), which are specific to each scene acquisition and dependent on land use class, soil background and atmospheric conditions.

Input land cover maps with spectrally homogeneous and functionally different land use classes were produced using the ISODATA unsupervised image classification algorithm of the image analysis software ENVI (ENVI 4.8, Exelis, UK). The number of land cover classes was initially set high and then reduced stepwise until the classification algorithm provided homogeneous classes which visually satisfied the representation of the surveyed fields and other fields in the landscapes. Water bodies, forest, urban/suburban area, roads and railways were further masked using the CORINE land cover map which has a spatial resolution of $100 \mathrm{~m}$ (Fig. 1) and the ESRI Streetmap Premium Europe Tele Atlas data set, using buffer zones of one pixel (10 or $20 \mathrm{~m})$. Greenhouses and polytunnels in the IT landscape were visually identified and masked using the SPOT image data.

Soil maps (1:1.100.000) from the European Soil Database (ESDB) of the European Soil Data Center (http://eusoils. jrc.ec.europa.eu/) were used as base soil maps for all landscapes except for Denmark, where a more detailed map comprising three classes (instead of two classes in the ESDB 
map) was available. For the UK site, it was observed that the CORINE category "peat bogs" was not well represented by the European soil map. The high organic content of these soils is likely to influence soil reflectance, and it was therefore decided to add the higher spatial resolution $(100 \mathrm{~m})$ CORINE "peat bogs" class as an additional soil class to the ESDB soil map.

The REGFLEC model was run using version 3 of the leaf optical properties model PROSPECT (Baret and Fourty, 1997). The NDVI threshold for intermediate vegetation density was set to 0.65 (used for selecting dense canopy pixels), and the leaf dry matter content was set uniformly to $55 \mathrm{~g} \mathrm{~m}^{-2}$ corresponding to the mean value estimated for leaf samples, except for the UK landscape, where it was set slightly lower $\left(50 \mathrm{~g} \mathrm{~m}^{-2}\right)$ due to the lower dry matter contents of natural grasses.

\section{Results}

\subsection{Landscape variations: vegetation index and LAI}

The mean and standard deviation (sd) of SPOT NDVI for the crop- and grassland areas within each $10 \mathrm{~km} \times 10 \mathrm{~km}$ study landscape is shown in relation to the NDVI seasonality represented by MODIS data (Fig. 4). The seasonality appeared quite similar in Denmark and Poland, with the maximal NDVI around 1 June 2008 corresponding to the timing of the SPOT image acquisitions. MODIS NDVI slowly increases towards the end of the year in both Denmark and Poland, due to emergence of autumn-sown crops such as wheat, barley and oilseed rape. Abrupt reductions in MODIS NDVI during winter are related to low solar angles and high frequency of overcast weather.

In the early-season SPOT image of DK09, peak NDVI has not yet been reached (Fig. 4), and lower overall vegetation cover is indicated by both NDVI and LAI compared with the DK08 landscape (Table 3). Nevertheless, the highest p pIR values are observed in DK09, which indicates the presence of very dense fields (Fig. 5). Two other groupings of high-density (red to dark green colours) $\rho_{\text {red }}-\rho_{\text {NIR }}$ data sets occur in the DK09 landscape (Fig. 5): one located at the lower boundary line of the $\rho_{\text {red }}-\rho_{\text {NIR }}$ scatterplot (denoted the "soil-line"), indicating presence of bare soils due to the low NIR reflectance of soils relative to the characteristic high NIR reflectance of leaves, and another, located in the intermediate $\rho_{\text {NIR }}$ range with relatively low $\rho_{\text {red }}$, indicating the presence of less densely vegetated fields. The mixture of bare fields (maize not yet sown), intermediate density fields (winter wheat) and very dense fields (winter oilseed rape) in DK09 results in largely contrasting values in this earlyseason satellite image.

Other landscapes with high-density soil-line formations (due to exposure of bare soils) are the IT and UK sites (Fig. 5). The UK site has a very short soil line represented
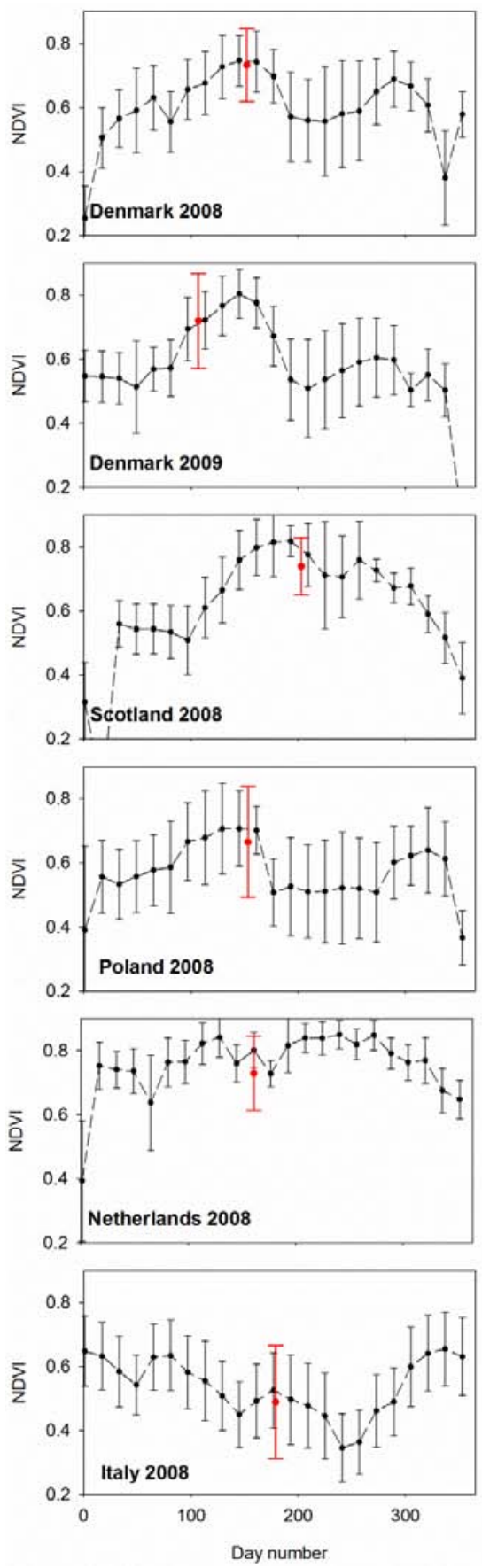

Fig. 4. Time series of average and standard deviation of NDVI for the agricultural area of each landscape extracted from MODIS data. The average and standard deviation NDVI calculated from each SPOT image of the agricultural region of NitroEurope landscapes is also shown. Due to different spatial resolutions of land use maps used for masking non-agricultural areas (1 km for MODIS), SPOT NDVI and MODIS NDVI are not representing exactly the same areas.

by low reflectance data, which likely represents dark organic (peat) soils, whereas the IT site has a much larger data spread 

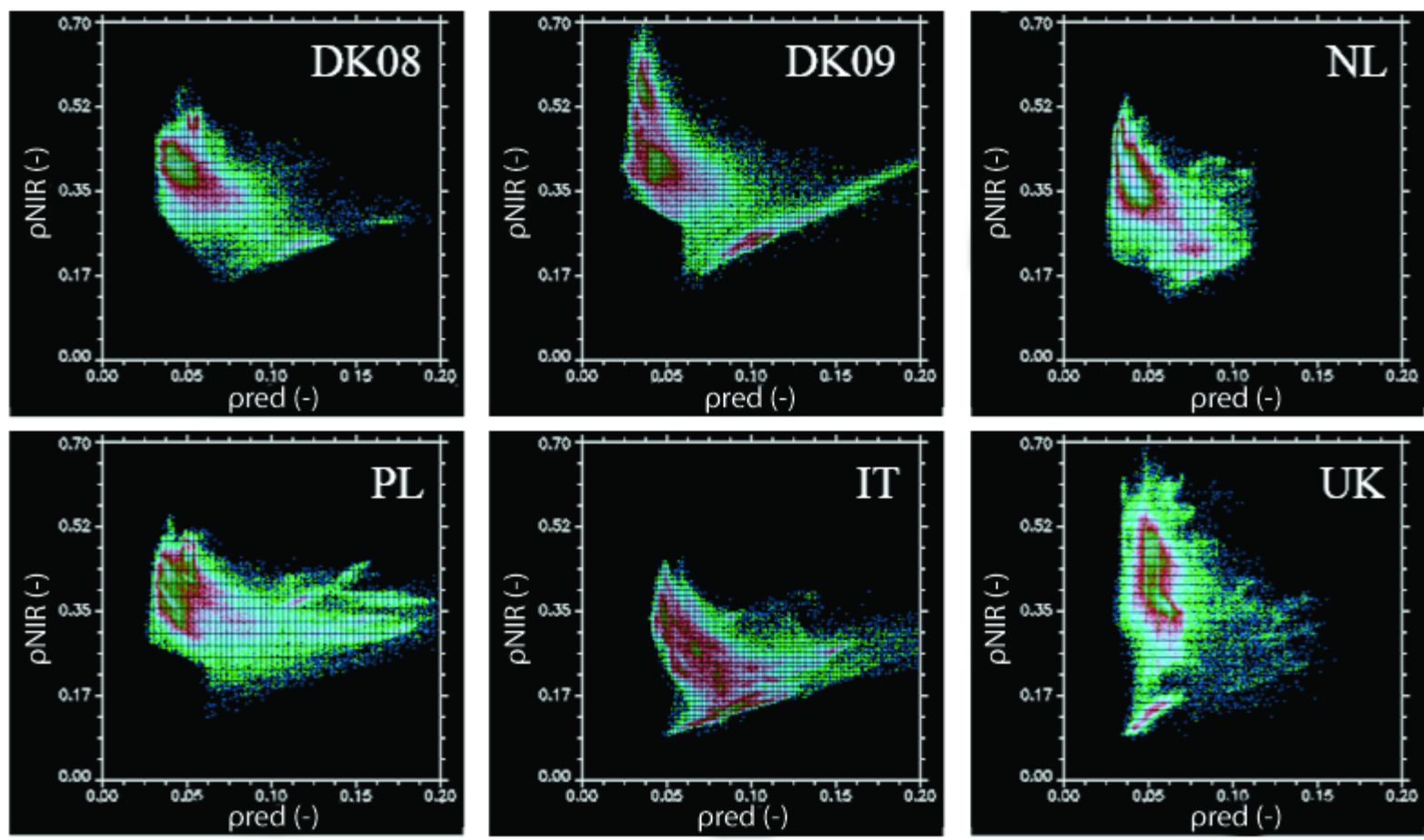

Fig. 5. Near infrared ( $\rho$ NIR) versus red surface reflectance ( $\rho$ red) of crop and grassland areas within each of the landscape sites calculated from SPOT satellite data. Data are shown as density scatter plots where the reddish and dark-green colours indicate the larger number (or density) of pixels representing the plotted ( $\rho$ red, $\rho$ NIR) data within each landscape.

(extended red region) along the soil line, which indicates larger spatial variability in soil background reflectance. The soil line of IT includes very low reflectance data, which is in good agreement with the prevailing Cambisols, also called brown soils, of this region. In IT, NDVI is lowest in summertime, and the NDVI seasonality indicates that harvesting takes place 2-3 times per year (Fig. 4). The low NDVI at the time of SPOT satellite imaging agrees with low LAI observations of widely spaced row-cropped vegetables in IT, and many bare fields were observed in the area. The overall lower vegetation cover of IT is also visualized by the $\rho_{\text {red }}-$ $\rho_{\text {NIR }}$ scatterplot (Fig. 5), where $\rho_{\text {NIR }}$ is clearly lower than for the other landscapes, and the bulk reflectance data (red colours) are indicating a prevalence of bare soils and sparseto-intermediate vegetation cover.

In the Scottish landscape (UK), the MODIS NDVI time series indicate that vegetation development started later in the year, compared with the DK and PL landscapes. SPOT satellite imaging took place about one month after peak NDVI is reached in UK (Table 1). Compared with the LAI measurements of the UK landscape, MODIS and SPOT NDVI are very high (Fig. 4 and Table 3) which indicates higher vegetation cover of the landscape than indicated by the LAI measurements of the seven fields (five grassland and two arable fields). NDVI is however sensitive to soil background reflectance, and the low background reflectance of dark (organic-rich) soils tends to increase the NDVI relative to the NDVI of a similar vegetation canopy with a bright soil background (Huete, 1988).

The grasslands of NL are characterized by high NDVI with low seasonal variation. However, NDVI was slightly reduced at the time of the SPOT satellite imaging, which may be indicative of recent grass cutting. A secondary group of highdensity reflectance pairs (red colours) in the lower part of the $\rho_{\text {red }}-\rho_{\text {NIR }}$ scatterplot (Fig. 5) supports the presence of recently cut fields with low residual vegetation cover.

\subsection{Landscape variations: chlorophyll and leaf nitrogen}

Despite the low vegetation coverage in IT, the vegetables cultivated at this site were characterized by the highest $\mathrm{CHL}_{1}$ and $\mathrm{N}_{1}$ concentrations (Table 3). The largest mean $\mathrm{N}_{1}$ concentrations occurred in artichokes $\left(7.82 \mathrm{~g} \mathrm{~m}^{-2}\right)$, tomatoes $\left(7.05 \mathrm{~g} \mathrm{~m}^{-2}\right)$ and alfalfa $\left(4.37 \mathrm{~g} \mathrm{~m}^{-2}\right)$, followed by oilseed rape $\left(3.11 \mathrm{~g} \mathrm{~m}^{-2}\right)$, wheat and barley $\left(2.22 \mathrm{~g} \mathrm{~m}^{-2}\right)$, grass $\left(1.54 \mathrm{~g} \mathrm{~m}^{-2}\right)$ and maize $\left(1.44 \mathrm{~g} \mathrm{~m}^{-2}\right)$. Measured canopy $\mathrm{N}$ contents $\left(\mathrm{N}_{\mathrm{c}}\right)$ are lowest in the UK landscape, which is dominated by semi-natural grassland, and highest in DK08 (Table 3). The $\mathrm{N}_{\mathrm{c}}$ estimate of fields in IT (Table 3) does not fully represent the field sites, due to incomplete representation of LAI for widely spaced rowcropped tomato fields. For $\mathrm{CHL}_{1}$, oilseed rape had the highest concentrations (mean $842 \mathrm{mg} \mathrm{m}^{-2}$ ). This was followed 

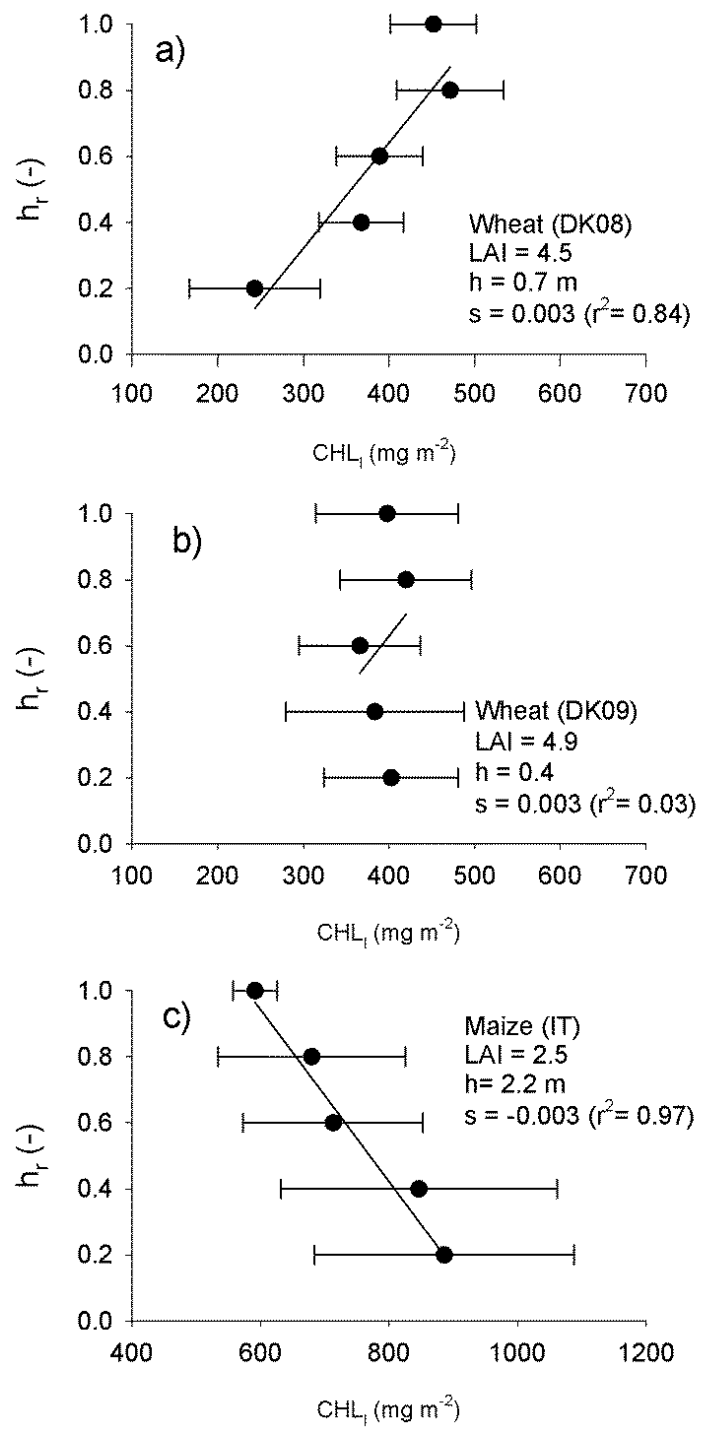

Fig. 6. Examples of three different characteristic vertical leaf chlorophyll $\left(\mathrm{CHL}_{1}\right)$ profiles based on field measurements within the studied landscape sites. The plots show mean and standard deviation $\mathrm{CHL}_{1}$ at relative measurement heights $\left(h_{r}=\right.$ measurement height divided by canopy height) and linear regression lines. Leaf area index (LAI), canopy height $(h)$, and the slope $(s)$ and determination coefficient $\left(r^{2}\right)$ of linear regression slopes are indicated in each graph. Note that the slope in (b) is not statistically significant.

by artichokes $\left(743 \mathrm{mg} \mathrm{m}^{-2}\right)$, tomatoes $\left(608 \mathrm{mg} \mathrm{m}^{-2}\right)$, alfalfa $\left(572 \mathrm{mg} \mathrm{m}^{-2}\right)$, wheat and barley $\left(390 \mathrm{mg} \mathrm{m}^{-2}\right)$, potatoes $\left(372 \mathrm{mg} \mathrm{m}^{-2}\right)$ and grasses $\left(340 \mathrm{mg} \mathrm{m}^{-2}\right)$.

Despite coefficients of variation $\left(\mathrm{CV}=\mathrm{sd} \mathrm{mean}^{-1}\right)$ in the range $20-35 \%$ for the mean $\mathrm{CHL}_{1}$ of fields within individual landscapes, the averaged within-field variation of $\mathrm{CHL}_{1}$ and $\mathrm{N}_{1}$ exceeded the between-field variability at the DK sites (Table 3). This highlights the importance of a consistent leaf measurement strategy for accurate ground-truth estimation of mean $\mathrm{CHL}_{1}$.
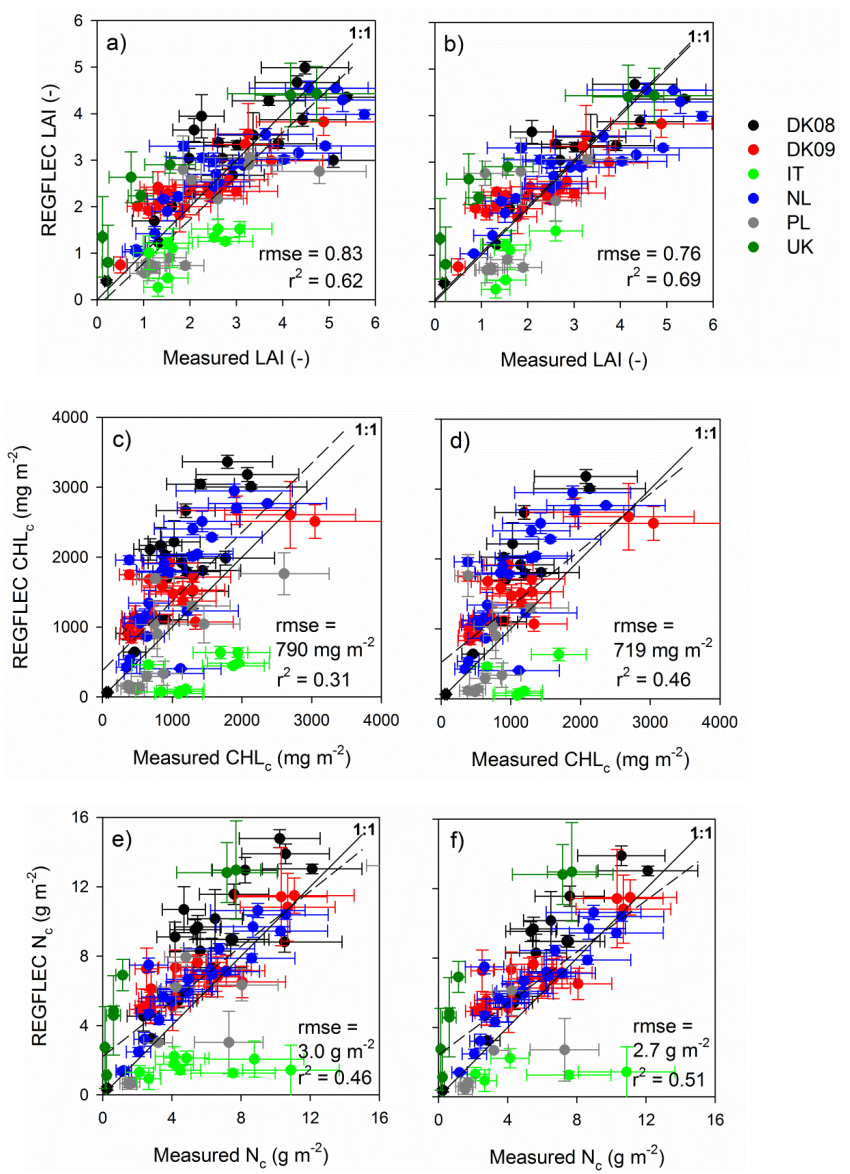

Fig. 7. Comparison of REGFLEC simulated LAI, $\mathrm{CHL}_{c}$ and $\mathrm{N}_{\mathrm{c}}$ for all field plots (left side graphs (a), (c) and (e)) and for "uniform field plots without strong in-canopy vertical $\mathrm{CHL}_{1}$ gradients (right side graphs (b), (d) and (f)). Error bars indicate the absolute total uncertainty for field data and the standard deviation $(3 \times 3$ pixels $)$ of REGFLEC simulations.

For nitrogen, the $\mathrm{CV}$ for mean $\mathrm{N}_{\mathrm{l}}$ of fields range between 8 and $68 \%$ for the different landscapes. Due to the larger species-specific variations in $\mathrm{N}_{1}$ than $\mathrm{CHL}_{1}$, between-field variation of mean $\mathrm{N}_{1}$ grossly exceeded the within-field variation in $\mathrm{N}_{1}$ at the IT and UK sites. The lowest between-field variability was observed in the DK09 (mostly wheat) and NL (mostly grass) landscapes (Table 3 ), which were characterized by more uniform land use.

\subsection{Within-canopy variations}

Three major types of within-canopy vertical $\mathrm{CHL}_{1}$ gradient profiles were evident in the leaf measurements across the European landscapes, which contribute to increase within-field variability in $\mathrm{CHL}_{1}$ and $\mathrm{N}_{1}$. Profiles either had $\mathrm{CHL}_{1}$ increasing from bottom to top of the canopy (Fig. 6a), uniform vertical $\mathrm{CHL}_{1}$ distributions (Fig. 6b) or decreasing $\mathrm{CHL}_{1}$ concentrations from bottom to top (Fig. 6c). Linear regression slope coefficients (s) and the coefficients of determination 
$\left(r^{2}\right)$ describing the relationships between $\mathrm{CHL}_{1}$ data and relative measurements heights $\left(h_{r}\right)$ can be used to indicate whether $\mathrm{CHL}_{1}$ profiles are increasing, decreasing or uniform (Fig. 6). It should be noted that distributions where $\mathrm{CHL}_{1}-$ $h_{r}$ regression slopes are characterized by low $r^{2}$ and thus characterized as uniform in this paper (Fig. 6b), are in reality often weakly S-formed or bell-shaped corresponding to what has been observed for maize in other studies (Ciganda et al., 2012; Winterhalter et al., 2012). In contrast, $\mathrm{CHL}_{1}-$ $h_{r}$ regression slopes with high $r^{2}$ and $s>0$ (Fig. 6a) or $s<0$ (Fig. 6c) have strong $\mathrm{CHL}_{1}$ vertical gradient profiles with increasing or decreasing gradients. Defining a strong $\mathrm{CHL}_{1}$ profile as a $\mathrm{CHL}_{1}-h_{r}$ relationship characterized by a statistically significant regression slope $\left(r^{2}>0.68 ; p<0.1\right)$, it was found that $26 \%$ of the total fields had strong vertical $\mathrm{CHL}_{1}$ gradient profiles. According to theoretical and experimental studies, exponentially decreasing $\mathrm{CHL}_{1}$ contents from top to bottom is the norm rather than the exception for densely vegetated canopies, and it occurred particularly frequently in the landscapes where crops were in a more mature stage, such as in DK08 (barley, wheat) and PL (oilseed rape, potatoes, alfalfa and barley). Decreasing $(s<0) \mathrm{CHL}_{1}$ profiles were observed in some maize fields in IT and NL. Generally the maize crops with lower canopies had more uniform $\mathrm{CHL}_{1}$ profiles, whereas tall $(>2 \mathrm{~m})$, irrigated and fertilized maize crops had strong "negative" $(s<0) \mathrm{CHL}_{1}$ vertical gradient profiles. $\mathrm{CHL}_{1}$ profiles are more uniform in the early season (19 April) DK09 landscape (only one field showed significant $\mathrm{CHL}_{1}$ vertical gradient profile), however decreasing $\mathrm{CHL}_{1}$ contents in the upper 1-2 measurement levels $\left(h_{r}=0.8-1\right)$ are normal and contributed to increase within-field $\mathrm{CHL}_{1}$ variability (Table 3 ).

\subsection{Remote-sensing-based LAI}

The REGFLEC model performed good for LAI estimation of all landscapes $\left(r^{2}=0.62\right.$; rmse $\left.=0.83 ; n=93\right)$ with a linear regression slope approaching unity $(0.93)$ and a small intercept (0.19) (Fig. 7a). Considering only uniform canopies with no $\mathrm{CHL}_{1}$ vertical gradient profiles $(n=76)$, the capability of REGFLEC to explain observed LAI variation further improved $\left(r^{2}=0.69\right.$; rmse $=0.76$; slope $=1.00$; intercept $=-0.02$; Fig. $7 \mathrm{~b}$ ) mainly due to better results in DK08 and PL, where strong positive $(s>0) \mathrm{CHL}_{1}$ vertical gradient profiles frequently occurred. Removal of canopies with vertical gradient $\mathrm{CHL}_{1}$ profiles improved the agreement between LAI data and REGFLEC estimations for all crop types (Table A1), including maize canopies which were characterized by negative $(s<0) \mathrm{CHL}_{1}$ vertical gradient profiles (rmse decreased from 0.82 to 0.54 ). The SVIs were also slightly better related to field measurements across the European landscapes when the "non-uniform" canopy field measurements were ignored (Fig. 8).

Considering only homogeneous canopies without strong vertical $\mathrm{CHL}_{1}$ gradient profiles (Table A1), REGFLEC was able to describe $71-75 \%$ of observed LAI variation of the major crop types, i.e. wheat, maize and barley across the European landscapes (rmse $=0.5-0.67$ ). The SVIs were also linearly or exponentially related to LAI of all wheat, maize, barley and grass fields, but for wheat and maize the SVIs (except EVI2) generally explained less (36-46\%) of the observed LAI variations despite being fitted to all data (Fig. 9a). This may be due to larger impact of variable background reflectance in these crops which are the most common European crop types and occur in four of the studied landscapes (Table 2). This suggestion is supported by the better capability of EVI2 (compared to other SVIs) to represent LAI variability (49-75\%) of wheat and maize (Fig. 9a), since EVI2 has been specifically designed to account for background variability. For wheat and maize, REGFLEC-LAI is better correlated with field data than any of the SVIs, and when all landscapes' field data are pooled, REGFLEC also represents better the observed LAI variations than any of the SVI's (Fig. 8). The relatively good LAI results of REGFLEC for wheat, maize and all (pooled) landscape data indicate overall good performance of REGFLEC to estimate LAI when surface variability increases.

Barley fields are in this study generally characterized by high LAI and thus a low range of LAI variability. For these dense canopies, the chlorophyll sensitive indices CI and GNDVI represent $90-94 \%$ of LAI variation of the restricted ("uniform") data set (Fig. 9a). It is also interesting to observe that for these relatively dense barley canopies, REGFLEC results and the SVIs are generally better related to $\mathrm{CHL}_{\mathrm{c}}$ and $\mathrm{N}_{\mathrm{c}}$ than to LAI (Fig. 9a-c). This suggests that remote sensing of LAI of dense canopies is more sensitive to leaf chlorophyll.

The accuracy of REGFLEC LAI estimates for homogeneous canopies in all the landscapes $(\mathrm{rmse}=0.76)$ is in the lower range of capabilities demonstrated in earlier REGFLEC applications ( $r m s e=0.4-0.75$ ). A slight tendency to saturate predictions for LAI values exceeding 4 may appear (Fig. 7a), however the saturation effect is much less than those of SVIs which are typically best related to LAI using exponential regression models (Table B1). Generally, better capability to represent LAI data variability is found within individual landscapes $\left(r^{2}=0.74-0.88\right)$, except for Italy, where REGFLEC performed less well $\left(r^{2}=0.59\right)$. In contrast, all SVIs explained between 67 and $78 \%$ of observed LAI variation of all fields in IT (Table B1), thereby confirming field data coherence. Poorer performance of REGFLEC in IT can be due to prevailing row crops in this landscape. Row crops do not comply with the homogeneous (turbid medium) canopy representation of CRTMs like ACRM (used by REGFLEC). It may also be due to a lack of image pixels representing dense vegetation of these rowcropped vegetables. The REGFLEC model requires the presence of dense vegetation fields of all land cover classes in order to parameterize the leaf and canopy properties that are required by the model to simulate $\mathrm{LAI}$ and $\mathrm{CHL}_{1}$. Furthermore, 


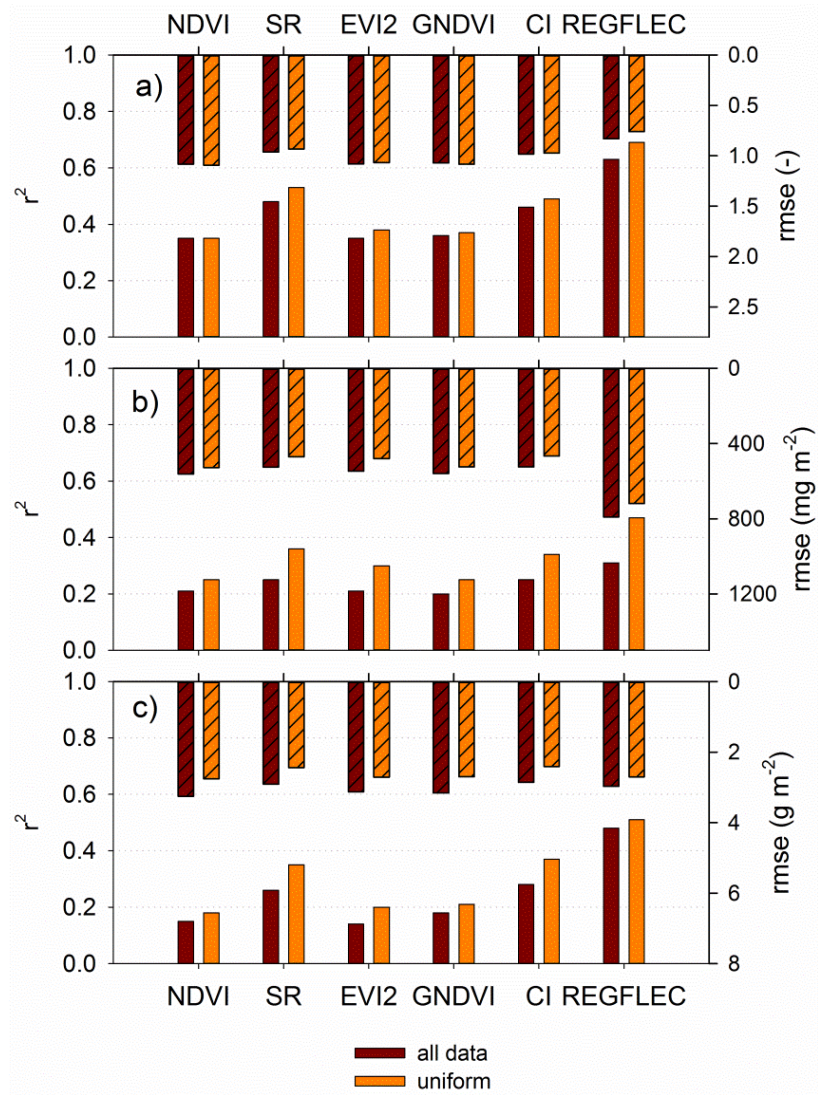

Fig. 8. Determination coefficients, $r^{2}$ (bars with no pattern), and root mean square errors, rmse (patterned bars), describing the relationships between remote-sensing-based calculations (REGFLEC simulations and five spectral vegetation indices) and field measurements of (a) LAI, (b) $\mathrm{CHL}_{\mathrm{c}}$ and (c) $\mathrm{N}_{\mathrm{c}}$ in five European landscapes. Results are shown separately when all field data are used for evaluation (brown bars) and when the field data set is restricted to comprise only canopies having "uniform" vertical chlorophyll profile gradients (orange bars). It should be noted that $r^{2}$ and rmse for SVIs represent results when fitted to all available field data whereas REGFLEC represents independent estimates.

the "background reflectance" of the IT site is very complex, due to vegetables and fruit trees being covered by nets for pest protection. In contrast to the SVIs, REGFLEC uses image information from the complete landscape, and not only for the field plots, for model parameterization. Removing (maize) canopies with strong vertical $\mathrm{CHL}_{1}$ profile gradients from the verification data set did not improve the performance of REGFLEC in IT. In this case, the reduced field data set (only five fields) is dominated by very sparse canopies. This decreases the range of vegetation cover data for REGFLEC evaluation, and it increases the sensitivity of remote sensing data to the large variability in background reflectance which was observed for the IT landscape (Sect. 4.1).

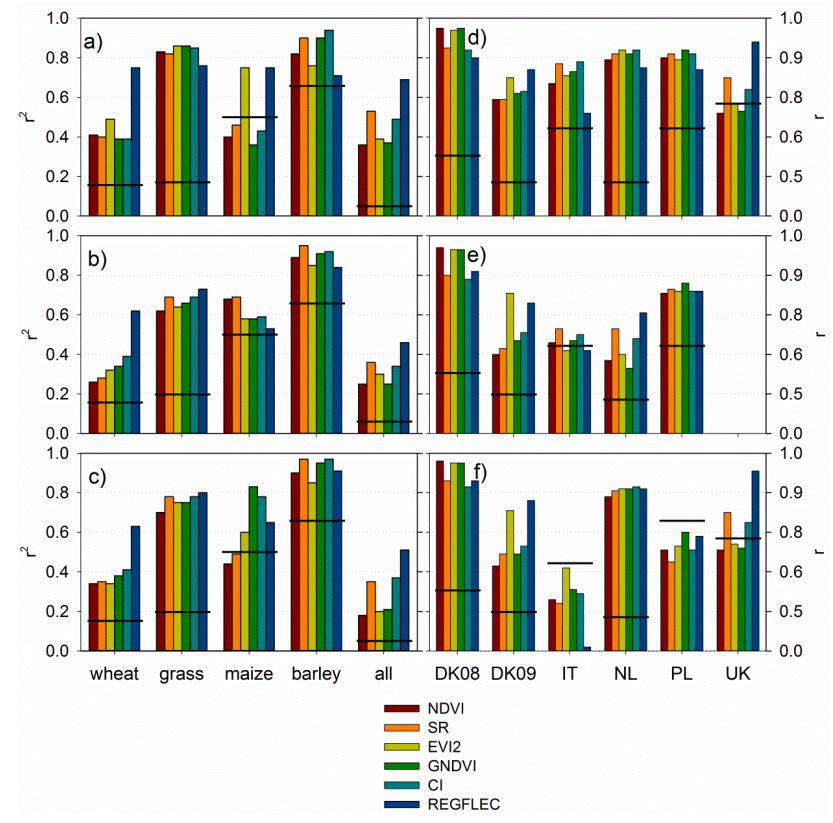

Fig. 9. Determination $\left(r^{2}\right)$ and correlation $(r)$ coefficients of the relationships between remote-sensing-based calculations (REGFLEC and five spectral vegetation indices) and field measurements of “ uniform" canopies without strong vertical $\mathrm{CHL}_{1}$ gradient (except for IT where all field data were included due to a limited number of "uniform" canopies. Please see Appendix B for all results). The left hand side shows results for (a) LAI, (b) $\mathrm{CHL}_{c}$ and (c) $\mathrm{N}_{\mathrm{c}}$ for different land use types and for all sites. The right hand side shows results for (d) LAI, (e) $\mathrm{CHL}_{\mathrm{c}}$ and (f) $\mathrm{N}_{\mathrm{c}}$ for the different landscapes. The horizontal lines illustrate the $95 \%$ confidence levels for significant correlation of each category examined. More detailed statistical results are included as tables in Appendices A and B.

\subsection{Remote-sensing-based $\mathrm{CHL}_{\mathrm{l}}$ and $\mathrm{N}_{\mathrm{l}}$}

No significant relationships were found between remotesensing-based measurements (REGFLEC simulations and SVIs) and leaf-scale $\mathrm{CHL}_{1}$ or $\mathrm{N}_{1}$. REGFLEC was however capable of reproducing $31 \%$ of observed variability in $\mathrm{CHL}_{\mathrm{c}}$ and $46 \%$ of observed $\mathrm{N}_{\mathrm{c}}$ variation when considering all measurement sites. When restricting the evaluation to canopies with uniform $\mathrm{CHL}_{1}$ vertical gradient profiles, REGFLEC represents better the observed variations in $\mathrm{CHL}_{\mathrm{c}}\left(r^{2}=0.46\right)$ and $\mathrm{N}_{\mathrm{c}}\left(r^{2}=0.51\right)$, and the same occurs for the SVIs (Fig. 8). REGFLEC estimates were generally less well related to $\mathrm{CHL}_{\mathrm{c}}$ than to LAI (Fig. 7), and they tend to be overestimated $\left(\mathrm{rmse}=719 \mathrm{mg} \mathrm{m}^{-2}\right)$. Overestimation of $\mathrm{CHL}_{\mathrm{c}}$ may partly be due to the use of one single SPAD meter calibration curve for all crops (Fig. 3). Only for barley, where field measurements of LAI were mostly high with low variability, was the linear correlation with $\mathrm{CHL}_{\mathrm{c}}\left(r^{2}=0.84\right)$ clearly much better than for LAI $\left(r^{2}=0.71\right)$, and the $\mathrm{CHL}_{\mathrm{c}}$ prediction error was low $\left(\mathrm{rmse}=446 \mathrm{mg} \mathrm{m}^{-2}\right)$. In IT, statistical confidence $(p<0.05)$ did not exist for significant correlations between 
Table 4. Percentage agricultural area (A), remote-sensing-based estimates of the average canopy nitrogen content $\left(\mathrm{N}_{\mathrm{c}}\right)$ of agricultural regions, and the total $\mathrm{N}_{\mathrm{c}}$ of the agricultural region within each of the $10 \mathrm{~km} \times 10 \mathrm{~km}$ landscape sites.

\begin{tabular}{lrrr}
\hline & $\begin{array}{r}\mathrm{A} \\
(\%)\end{array}$ & $\begin{array}{r}\mathrm{N}_{\mathrm{c}} \\
\left(\mathrm{g} \mathrm{m}^{-2}\right)\end{array}$ & $\begin{array}{r}\mathrm{N}_{\mathrm{c}} \\
(t)\end{array}$ \\
\hline DK08 & 48 & 5.93 & 307.33 \\
DK09 & 48 & 1.40 & 64.72 \\
UK & 77 & 1.43 & 110.56 \\
PL & 78 & 5.14 & 401.29 \\
NL & 69 & 4.04 & 277.97 \\
IT & 49 & 5.91 & 198.34 \\
\hline
\end{tabular}

REGFLEC results and the observations of $\mathrm{CHL}_{\mathrm{c}}$ and $\mathrm{N}_{\mathrm{c}}$ (Fig. 9).

Overall, the results based on the pooled landscape data are strongly deteriorated by the underestimation of $\mathrm{N}_{\mathrm{c}}$ and $\mathrm{CHL}_{\mathrm{c}}$ in IT (Fig. 7). If IT data are excluded, REGFLEC performance $\left(r^{2}\right)$ would increase from 0.51 to 0.69 for $\mathrm{N}_{\mathrm{c}}$ and from 0.46 to 0.59 for $\mathrm{CHL}_{\mathrm{c}}$. As for the LAI estimations, REGFLEC was a stronger predictor of $\mathrm{CHL}_{\mathrm{c}}$ and $\mathrm{N}_{\mathrm{c}}$ data of wheat (but not for maize due to poorer results in IT) than the SVIs (Fig. 9). This is expected to be due to the relatively better performance of REGFLEC in environments of strong background variability, such as in the four landscapes where wheat fields occur. In IT and PL where the high land use diversity (Table 2) causes large species-dependent variations in $\mathrm{N}_{\mathrm{c}}$, SVIs are not statistically significantly related to $\mathrm{N}_{\mathrm{c}}$. In IT, negative relationships between SVIs and $\mathrm{N}_{c}$ are achieved due to the much higher $\mathrm{N}$ contents of vegetables. REGFLEC is able to describe $76 \%$ of $\mathrm{N}_{\mathrm{c}}$ variation in PL (but not IT, as already discussed) when using the species-specific $\mathrm{CHL}_{1}-\mathrm{N}_{1}$ relationships (Fig. 3c) to convert REGFLEC simulated CHL to $\mathrm{N}_{1}$. In general, 76-91\% of $\mathrm{N}_{\mathrm{c}}$ data variability could be explained by REGFLEC for the individual European landscapes (except IT), however the rmse's range from 1.58 to $4.37 \mathrm{~g} \mathrm{~m}^{-2}$ with errors being highest in the UK, where the regression line differed significantly from one (Table B3). When excluding data from IT, REGFLEC was capable of explaining $69 \%$ of $\mathrm{N}_{\mathrm{c}}$ variation in the European landscapes, however rmse remains rather large $\left(2.4 \mathrm{~g} \mathrm{~m}^{-2}\right)$.

\subsection{Vegetation nitrogen pools of European landscapes}

Even though REGFLEC results were found to be statistically significant related to the pooled data of LAI, $\mathrm{CHL}_{\mathrm{c}}$ and $\mathrm{N}_{\mathrm{c}}$ in all landscapes, closer relationships between field data and REGFLEC results were achieved when restricting the evaluation to separate landscapes (Appendix B). In order to minimize the uncertainty of vegetation $\mathrm{N}$ pool assessments of European landscapes in this study, the best performing linear or exponential regression model in each landscape (for SVIs and REGFLEC results) was used to quantify the size of land- scape vegetation $\mathrm{N}$ pools. The best regression models (with lowest rmse and highest $r^{2}$ ) were derived from the restricted data set representing canopies without strong $\mathrm{CHL}_{1}$ profile gradients and applied to all field plots. Generally, rmse's of the best performing linear or exponential regression models within individual landscapes varied from 0.28 to 0.68 for LAI. Combining the best regression models increased overall LAI accuracy (Fig. 10a) slightly for the six European landscape images so that $76 \%$ of total data variability could be represented (rmse $=0.66$ ). Combining the best $\mathrm{CHL}_{\mathrm{c}}$ regression models results in being able to explain $64 \%$ of total $\mathrm{CHL}_{\mathrm{c}}$ data variability (rmse $=362 \mathrm{mg} \mathrm{m}^{-2}$ ) and $76 \%$ of total $\mathrm{N}_{\mathrm{c}}$ data variability $\left(\mathrm{rmse}=1.84 \mathrm{~g} \mathrm{~m}^{-2}\right)$ within the five European landscapes (Fig. 10). Because no SVI-N $\mathrm{N}_{\mathrm{c}}$ regression model can represent the strong species-dependent leaf $\mathrm{N}$ contents of vegetable fields in Italy, the best performing SVI-CHL ${ }_{c}$ regression model (i.e. SR is the best SVI in IT) was instead applied, and species-specific $\mathrm{CHL}_{1}-\mathrm{N}_{1}$ relationships (Fig. 3c) were then used to convert the SR-based $\mathrm{CHL}_{\mathrm{c}}$ to $\mathrm{N}_{\mathrm{c}}$. It should be noted that the regression models used to produce Fig. 10 were not independently validated, and the results represent the effects of data fitting in the different landscapes.

The resulting maps of $\mathrm{N}_{\mathrm{c}}$ illustrate large spatial variations in land use structure with many small fields being responsible for small-scale variations in the vegetation $\mathrm{N}$ pools of cropand grasslands (Fig. 11). Generally the largest vegetation $\mathrm{N}$ pools were found in DK08 and PL whereas the smallest vegetation $\mathrm{N}$ pools were found in UK (Table 4). However these overall comparisons should be interpreted with care for PL and IT due to the lower statistical confidence in these landscapes (Fig. 9f). The remote-sensing-based landscape averaged estimates of mean $\mathrm{N}_{\mathrm{c}}$ for PL and IT are however in good agreement with the observed mean $\mathrm{N}_{\mathrm{c}}$ (Fig. 12).

Mean $\mathrm{N}_{\mathrm{c}}$ based on field measurements tended to exceed the landscape averaged $\mathrm{N}_{\mathrm{c}}$ predictions in UK and NL, but very good agreements were observed for the other sites (Fig. 12). In NL, low landscape $\mathrm{N}_{\mathrm{c}}$ was probably related to the cutting of some grass fields shortly before the SPOT image was taken (Fig. 4), and in UK, the extensive grasslands are responsible for the low $\mathrm{N}_{\mathrm{c}}$ of this landscape (Fig. 12). The largest landscape $\mathrm{N}_{\mathrm{c}}$ were found for DK08, IT and PL (with lower confidence in IT and PL) where an average of $5.66 \mathrm{t} \mathrm{N}_{\mathrm{c}} \mathrm{km}^{-2}$ was estimated for the agricultural area (Table 4). Due to the larger proportion of agricultural area in PL, the total landscape $\mathrm{N}_{\mathrm{c}}\left(4.01 \mathrm{t} \mathrm{N}_{\mathrm{c}} \mathrm{km}^{-2}\right)$ stored in crops was largest overall for this study area (Table 4). Large spatial variations were found in both measured and predicted $\mathrm{N}_{\mathrm{c}}$ within and between the landscapes which can be attributed to seasonal variations, land use and spatial variations in resource (water and nutrients) availability. Frequency distributions of $\mathrm{N}_{\mathrm{c}}$ (Fig. 12) are negatively skewed in DK08 and PL, indicating prevalence of fields with dense (and mature) vegetation, and with $\mathrm{N}_{\mathrm{c}}$ reaching higher values in DK08 than in PL. $\mathrm{N}_{\mathrm{c}}$ distributions are positively skewed in NL and IT with largest 

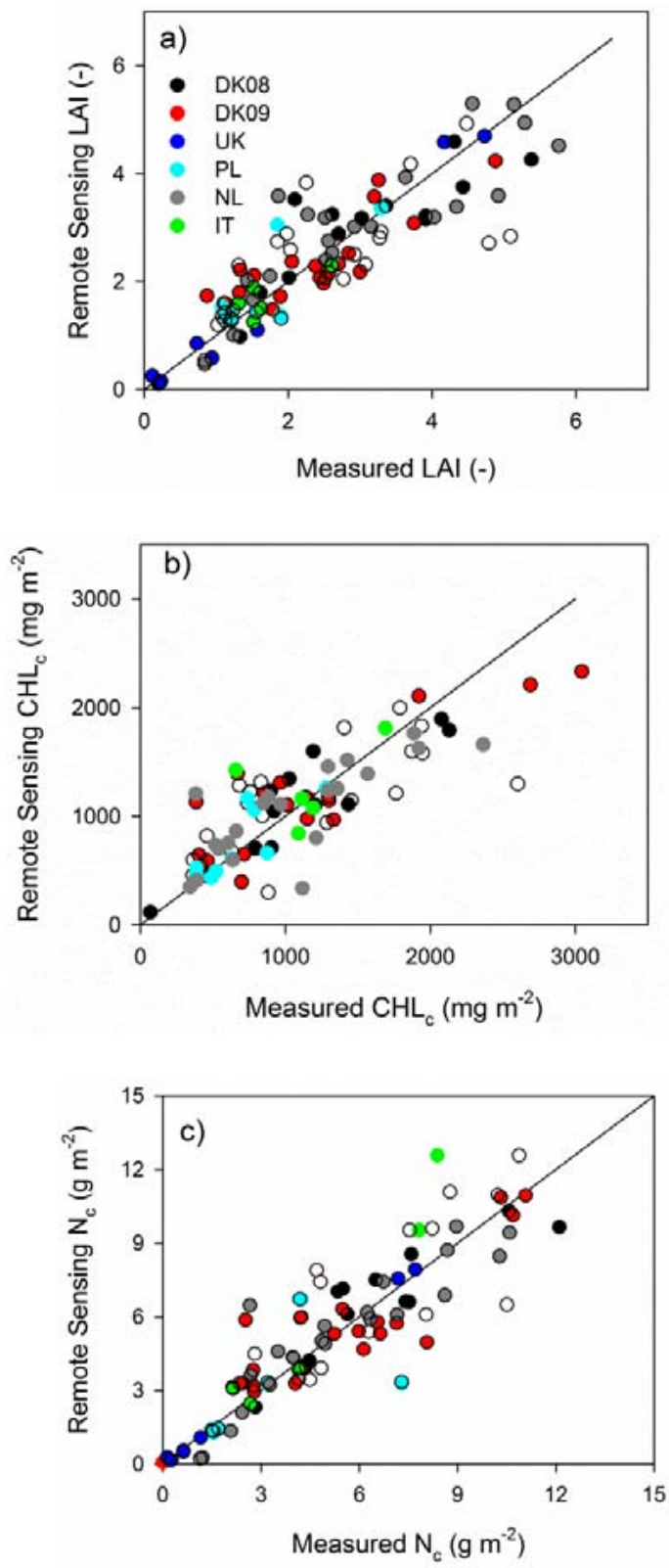

Fig. 10. Comparison of field measurements and remote-sensingbased estimates of (a) LAI, (b) $\mathrm{CHL}_{c}$ and (c) $\mathrm{N}_{\mathrm{c}}$ of homogeneous canopies without strong chlorophyll vertical profile development. The remote-sensing-based estimates in each landscape are based on the regression models that were best correlated with field data representing "uniform" canopies without strong vertical $\mathrm{CHL}_{1}$ profile gradients (Appendix B). Canopies with uniform $\mathrm{CHL}_{1}$ profiles are represented using coloured symbols and the empty circles represent other canopies.

spatial variation in IT; and it is strongly positively skewed in DK09 and UK due to the large fractional areas with sparse vegetation (DK09) and/or low $\mathrm{N}_{1}$ contents of grasses (UK). It was not possible to find measured or modelled estimates of $\mathrm{N}_{\mathrm{c}}$ in the scientific literature for comparison.

\section{Discussion}

\subsection{Remote sensing predictabilities for $\mathrm{LAI}, \mathrm{CHL}_{c}$ and $\mathbf{N}_{\mathbf{c}}$}

Generally it is recognized that site- or vegetation-specific empirical corrections or model parameterizations are needed to achieve accurate $\mathrm{LAI}$ and $\mathrm{CHL}_{1}$ estimations from regional applications of remote sensing data. These findings are also reflected in the present study where the SVIs and REGFLEC results were generally better related to vegetation measurements when the data set was constrained to represent single land use categories. The remote-sensing-based SVIs and REGFLEC results were even better related to field measurements when the comparison was constrained to represent local $(10 \mathrm{~km} \times 10 \mathrm{~km})$ landscapes, with the exception of $\mathrm{N}_{\mathrm{c}}$ prediction for landscapes with very heterogenous land use (IT and PL) (Fig. 9f). This highlights the important need to account for surface type variability when applying remote sensing methods over larger regions. The REGFLEC model is designed to automatically correct for soil- and vegetationclass specific properties. In this context, it was encouraging to find that REGFLEC performs relatively better than the SVIs when applied across the European landscapes despite being a data-independent method. It was also noted that REGFLEC performs best in landscapes comprising large contrasts in vegetation cover, ranging from bare soil to dense vegetation, such as for the early season DK09 landscape. REGFLEC needs such variability to parameterize the soiland vegetation-class specific properties of the canopy radiative transfer model that it uses.

Overall, REGFLEC results were able to describe 69, 46 and $51 \%$ of observed variations in $\mathrm{LAI}, \mathrm{CHL}_{\mathrm{c}}$ and $\mathrm{N}_{\mathrm{c}}$ of all landscapes. However, better results were obtained when excluding IT from the evaluation due to insufficient availability of dense vegetation covers for crop parameterization, and the row-cropped pattern is also expected to challenge REGFLEC performance in IT. One reason for the relatively good performance of both REGFLEC and SVIs is related to selecting a subset of field data so that only homogeneous canopies without $\mathrm{CHL}_{1}$ vertical gradient profiles were used to evaluate predictions. Since an exponential decline in $\mathrm{CHL}_{1}$ with depth in the canopy is normally expected for dense canopies, this highlights the need for careful leaf measurement strategies in remote sensing studies of vegetation.

For individual landscapes, except IT, REGFLEC LAI performance $\left(r^{2}=0.74-0.88\right.$; rmse $\left.=0.6-1.14\right)$ was comparable to or better than what was found using empirical (datadependent) broad-band SVIs in this (Fig. 9) and other studies. For instance, Viña et al. (2011) evaluated the performance of eight SVIs for LAI prediction of two crop types with contrasting canopy structures (maize and soybean) and found values of rmse in the range 0.58-2.53 (median 0.88) with the best results given by a narrowband red-edge chlorophyll index. Better LAI accuracies (rmse down to 0.4) were 

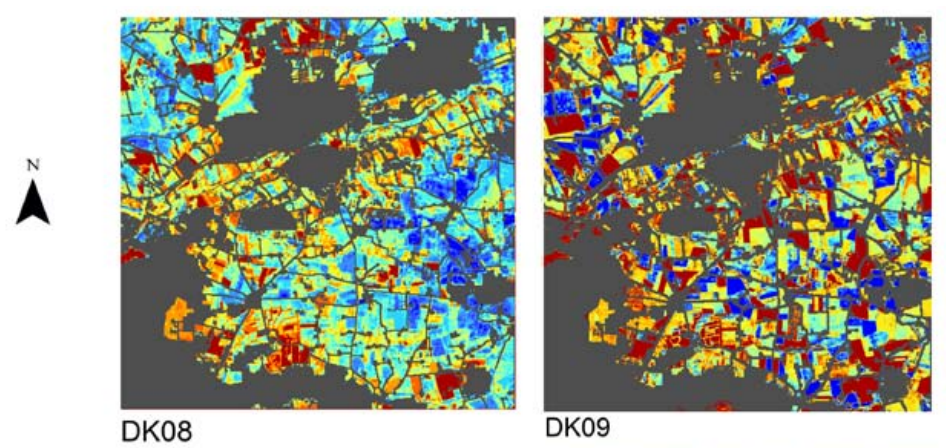

DK09

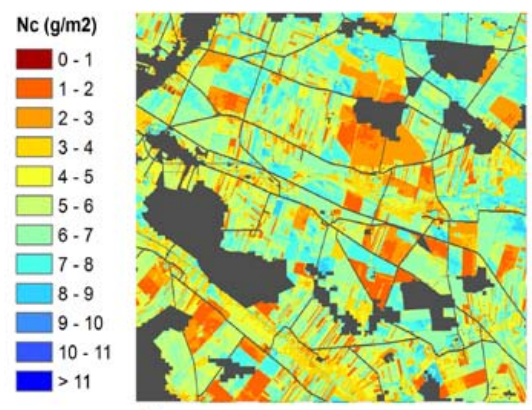

$\mathrm{PL}$

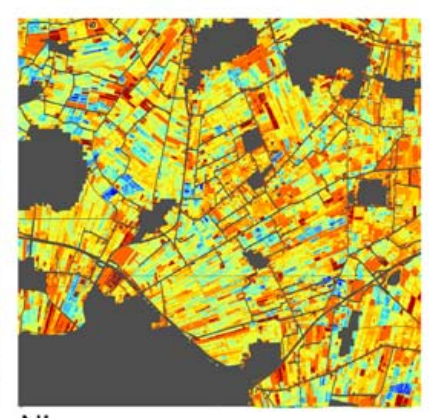

$\mathrm{NL}$

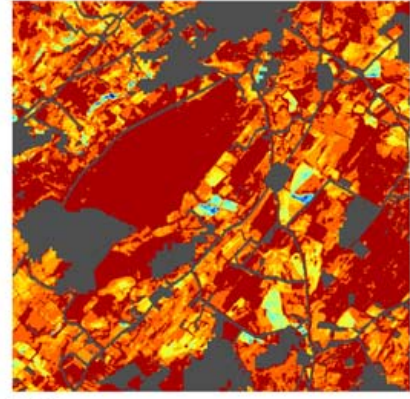

UK

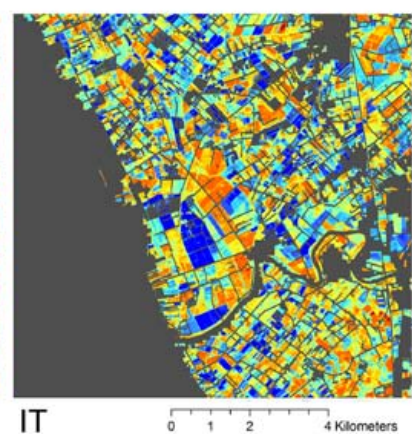

Fig. 11. Remote-sensing-based maps of $\mathrm{N}_{\mathrm{c}}$ of NitroEurope agricultural landscape sites located in Denmark (DK08, DK09), Scotland (UK), Poland (PL), the Netherlands (NL) and Italy (IT). Water, urban/suburban (including streets) and forest areas are shown in dark grey. Frequency distributions of $\mathrm{N}_{\mathrm{c}}$ are shown in Fig. 12.

obtained in previous REGFLEC applications (Houborg et al., 2007; Houborg and Boegh, 2008; Houborg and Anderson, 2009) and by Atzberger and Richter (2012), who used pixel neighbourhood information to regularize inverse model predictions of LAI for three crops ( $r m s e=0.54$ ). The high accuracies reported for LAI in these studies were however comparable to the rmse of REGFLEC when applied to the DK09 site in the current study (rmse $=0.6)$.

Generally, REGFLEC performance ( $r^{2}$ and rmse) for LAI estimation was better than for $\mathrm{CHL}_{\mathrm{c}}$ and $\mathrm{N}_{\mathrm{c}}$. Darvishzadeh et al. (2008) also found that remote-sensing-based predictability for LAI was better than for $\mathrm{CHL}_{\mathrm{c}}$ (using inverse radiative modelling of hyperspectral data), but that $\mathrm{CHL}_{\mathrm{c}}$ predictability exceeded LAI predictability when the number of species was increased. This is not the case in the current study where landscape predictability of LAI tends to be better than for $\mathrm{CHL}_{\mathrm{c}}$ and $\mathrm{N}_{\mathrm{c}}$ estimation (Fig. 9d-f), however for dense barley fields, both REGFLEC and SVIs explained better variations in $\mathrm{CHL}_{\mathrm{c}}$ due to observed low LAI variation.

Field-spectrometric studies based on hyperspectral and narrowband reflectance data showed that $\mathrm{CHL}_{c}$ can be retrieved with rmse of $310-320 \mathrm{mg} \mathrm{m}^{-2}$ when considering 12 species (Gitelson et al., 2005; Darvishzadeh et al., 2008), and when including more species, such as in a heterogeneous grassland, rmse increased to $440 \mathrm{mg} \mathrm{m}^{-2}$ (Darvishzadeh et al., 2008). Using broad-band (MODIS) reflectance data, rmse increased to $690 \mathrm{mg} \mathrm{m}^{-2}$ (Gitelson et al., 2005). These results are better than the accuracy of REGFLEC when applied to the six landscape cases in this study (rmse $=719 \mathrm{mg} \mathrm{m}^{-2}$ ). It should be mentioned however that field data uncertainties for $\mathrm{CHL}_{\mathrm{c}}$ are quite high in the current study (Fig. 7c, d) due to scarcity of laboratory $\mathrm{CHL}_{1}$ analyses (in particular for alfalfa and artichokes) and the use of one single SPAD meter calibration curve for all species in all countries (Fig. 3a). However, REGFLEC predictions explain much of observed $\mathrm{CHL}_{\mathrm{c}}$ variability in the European landscapes (61-82\%), except IT, as do also the SVIs (Fig. 9e). The best fitted SVI regression models within individual landscapes are related to $\mathrm{CHL}_{\mathrm{c}}$ with rmse's in the range $244-387 \mathrm{mg} \mathrm{m}^{-2}$ which is comparable to what was found in other SVI studies.

Some studies found that leaf-scale CHL can be predicted from image data with rmse in the range $40-90 \mathrm{mg} \mathrm{m}^{-2}$ (Houborg and Boegh, 2008; Houborg and Anderson, 2009; Atzberger and Richter, 2012). Even though REGFLEC has shown such capabilities in previous studies, it was not possible to achieve statistical confidence for $\mathrm{CHL}_{1}$ prediction in this study. This may have been due to insufficient bare soil pixels in the growing season to establish a robust soil parameterization for each soil class. In this case, a solution could be to include a satellite image from before the growing season to improve the soil parameterization, as shown by Houborg and Boegh (2008).

While chlorophyll can be predicted using species-specific model parameters (as used by REGFLEC), remote-sensingbased $\mathrm{N}_{\mathrm{c}}$ estimation is further complicated by the dependence of $\mathrm{CHL}_{1}: \mathrm{N}_{1}$ ratios of leaves on local light climate. 


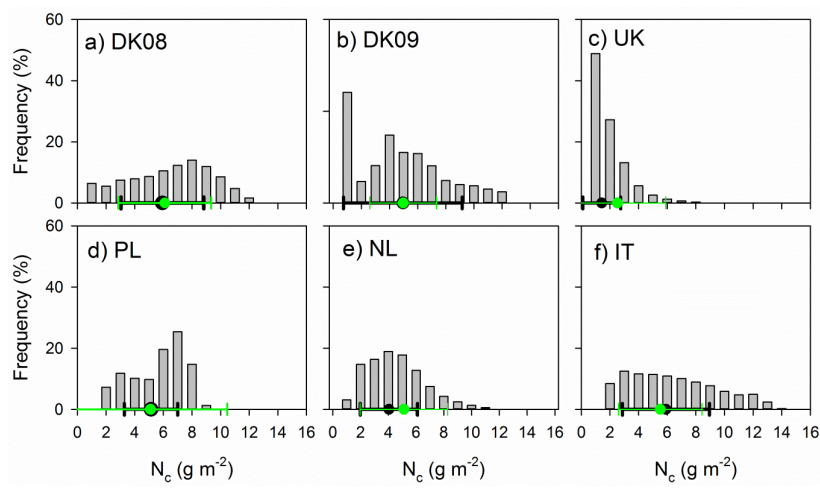

Fig. 12. Frequency distributions of $\mathrm{N}_{\mathrm{c}}$ contents of crop- and grasslands in NitroEurope landscapes (mapped in Fig. 11) estimated using remote sensing for the (a) Danish site, 31 May 2008, (b) Danish site, 19 April 2009, (c) Scottish site, 21 July 2008, (d) Polish site, 1 June 2008, (e) Dutch site, 9 June 2008 and (f) Italian site, 27 June 2008. The mean and standard deviation of field measurements are also indicated (green dot), and the mean and standard deviation of the remote-sensing-based estimations are shown (black dot).

The use of narrowband indices for a single species (without variations in soil background) has given significantly better estimates for $\mathrm{N}_{\mathrm{c}}$ than those found for the separate land use categories in this study (rmse $=1.1-2.8 \mathrm{~g} \mathrm{~m}^{-2}$ ). For instance, Fitzgerald et al. (2010) applied three spectral bands in the red-edge zone to a triangular SVI approach and found that $\mathrm{N}_{\mathrm{c}}$ of wheat could be retrieved with rmse of $0.65 \mathrm{~g} \mathrm{~m}^{-2}$. Hansen and Schjoerring (2002) used an optimal narrowband NDVI to achieve $\mathrm{N}_{\mathrm{c}}$ for wheat with rmse of $0.8 \mathrm{~g} \mathrm{~m}^{-2}$.

Effects of within-canopy $\mathrm{CHL}_{1}$ variations on surface reflectance have only recently been considered in remote sensing studies, but this study showed that it could have an effect on the remote-sensing-based predictability of LAI, $\mathrm{CHL}_{\mathrm{c}}$ and $\mathrm{N}_{\mathrm{c}}$. It should be noticed that the $\mathrm{CHL}_{1}$ profiles observed in this study were frequently characterized by weak S-formed or bell-shaped forms, and that such canopies were included in our reduced validation data set because of their insignificant $\mathrm{CHL}_{1}-h_{r}$ slopes. It is possible that other criteria or more advanced data integration techniques would be more effective to evaluate the relationships between remote sensing measurements and vegetation field data such as LAI and $\mathrm{CHL}_{1}$. Some CRTMs consider vertical variation in canopy structure using two layers to represent colour gradients, clumping and tree crowns (Verhoef and Bach, 2008). Also, socalled functional-structural plant models (Godin and Sinoquet, 2005) are being used to study 3-D interaction between light absorption and biological processes such as canopy growth. However these modelling approaches have focused on representing light scattering effects of canopy structure (e.g. Casa et al., 2010). The results from the current study suggests that within-canopy $\mathrm{CHL}_{1}$ variability should be measured in remote sensing studies of vegetation, and that such variations may help to better understand the reasons for the successes and failures of different remote sensing methods to quantify LAI, $\mathrm{CHL}_{\mathrm{c}}$ and $\mathrm{N}_{\mathrm{c}}$.

\subsection{Remote sensing and carbon-nitrogen dynamics}

The problem of scale is considered one of the largest challenges to providing robust global and European greenhouse gas budgets for croplands (Osborne et al., 2010). Current global estimates use plot-scale determinations which may have only local or regional relevance or large-scale remote sensing techniques which do not resolve local or regional differences (Osborne et al., 2010). Even though remote sensing data are frequently used to assess chlorophyll and leaf nitrogen for crop precision management, methods are developed and tested using plot-scale data, and they are often considered to lack the required accuracy and precision to reflect temporal and/or spatial heterogeneity for regional carbon budget modelling of croplands (e.g. Wattenback et al., 2010). The current study showed that high spatial resolution remote sensing of selected landscapes representing crop- and grasslands over a large gradient of environmental conditions in Europe can explain $69 \%$ of LAI variation $(\mathrm{rmse}=0.76$ ), $46 \%$ of $\mathrm{CHL}_{\mathrm{c}}$ variation $\left(\mathrm{rmse}=719 \mathrm{mg} \mathrm{m}^{-2}\right.$ ) and $51 \%$ of $\mathrm{N}_{\mathrm{c}}$ variation $\left(\mathrm{rmse}=2.7 \mathrm{~g} \mathrm{~m}^{-2}\right.$ ) using a data-independent physically based model approach (REGFLEC). Better results could be obtained when applying regression model building to individual landscapes (Fig. 10). The findings support the use of remote sensing data to characterize spatial variability in vegetation traits thereby improving the representation of site-specific effects of field management practice for regional water, carbon and nitrogen cycle modelling (e.g. Boegh et al., 2004; Houborg et al., 2007; Boegh et al., 2009; Gitelson et al., 2009; Ciais et al., 2010; and Houborg et al., 2011). The sensitivity of model studies relative to the accuracy of remote-sensing-based predictions should however be assessed.

Leaf nitrogen is a key driver for biogeochemical cycling through its significance for photosynthesis and respiration modelling (e.g. Boegh et al., 2002; Kattge et al., 2009; and Houborg et al., 2011), and it is also found to be important to assess the stomatal $\mathrm{NH}_{3}$ compensation point, which determines whether vegetation canopies act as a source or a sink for $\mathrm{NH}_{3}$ (Massad et al., 2008). In a global study of leaf nitrogen variability (Freschet et al., 2011), it was found that as much as $50 \%$ of the variability occurred within communities whereas $15 \%$ occurred between communities and $35 \%$ of global variance occurred between biomes. These results indicate that a significant part of global plant trait variation cannot be described using broad-scale influences (e.g. climate and topography) but that variations exist within plant communities at a fine spatial scale.

While many natural ecosystems are nutrient limited, the nitrogen balance of agricultural areas is generally positive in Europe. This means that there is a nitrogen surplus which contributes to nitrogen leaching, nitrous oxide emission 
(Schelde et al., 2012) and ammonia volatilization (Sutton et al., 2007). However, there are large variations within different European landscapes that are dependent on agricultural systems such as livestock production and the use of manure and inorganic fertilizers (e.g. Dalgaard et al., 2012). Since foliage $\mathrm{N}_{1}$ is closely related to nitrogen additions and soil mineral availability (Song et al., 2011), remote-sensingbased $\mathrm{N}_{\mathrm{c}}$ estimates may provide useful information to design field sampling strategies and adjust the simulations of agro-ecosystem models to partition deposited nitrogen between plants and soils. Together with measurements of nitrogen emissions and flows in landscapes, spatial information of biomass nitrogen pools are important to improve the understanding of nitrogen availability effects on the green house gas budget of terrestrial ecosystems (e.g. Schulze et al., 2010). In this study, it was found that "snapshots" of biomass nitrogen pools varied widely within and between five European agricultural landscapes, with the lowest $\mathrm{N}$ pool found in the UK landscape $\left(110.56 \mathrm{t} \mathrm{km}^{-2}\right)$, and the largest pool found in PL ( $401.29 \mathrm{t} \mathrm{km}^{-2}$ ) due to the larger proportion of agricultural area. Despite DK having the lowest proportional area of agricultural land, the second-highest $\mathrm{N}$ pool was found there (DK08, 31-May). The largest $\mathrm{N}$ concentrations within agricultural areas were found in DK08, IT and PL.

This article demonstrated the capability of high spatial resolution data to provide spatial estimates of LAI, chlorophyll and leaf nitrogen pools with statistical confidence for a subset of landscapes located over an extended region (Europe). With the launch of the upcoming European Sentinel-2 satellite mission (scheduled for 2013), 13 spectral bands will be available in the red-shortwave infrared at high spatial resolution $(10-60 \mathrm{~m})$ with three new bands located in the rededge region. This would support the use of additional narrowbands with optimized sensitivity to changes in $\mathrm{CHL}_{1}$ and with reduced sensitivity to confounding factors. The availability of Sentinel-2 data would significantly advance the ability to monitor plant physiological condition both in terms of retrieval accuracy and spatio-temporal resolution $(20 \mathrm{~m}$ every 2-5 days) using SVIs and a tool such as REGFLEC.

\section{Conclusions}

The REGFLEC model was found to describe $69 \%$ of LAI variation, $46 \%$ of $\mathrm{CHL}_{\mathrm{c}}$ variation and $51 \%$ of $\mathrm{N}_{\mathrm{c}}$ variation when applied at high spatial resolution for five contrasting landscapes representing European crop- and grasslands $\left(\right.$ LAI rmse $=0.76 ; \mathrm{CHL}_{\mathrm{c}}$ rmse $=719 \mathrm{mg} \mathrm{m}^{-2} ; \mathrm{N}_{\mathrm{c}}$ $\mathrm{rmse}=2.7 \mathrm{~g} \mathrm{~m}^{-2}$ ). Better results were achieved for the individual landscapes, except for one very sparsely vegetated landscape (Italy). This strongly supports the applicability of such products to characterize spatial variability in vegetation traits for regional simulation and upscaling of water, carbon and nitrogen cycles.
The use of simpler SVI approaches also provided statistically significant results when calibrated against field data representing a variety of grasses and crop types, but the dataindependent REGFLEC approach provided the best results over a large range of environmental conditions (soils, surface types, atmosphere). In particular, a large range in vegetation cover is needed by REGFLEC for each land use type for successful application of the automatic spatial regularization technique (REGFLEC) which facilitates the parameterization of an image-based atmospheric-leaf optics-CRTM model. In one landscape, Italy, the range of vegetation cover was too low to allow such parameterization for all land use types, and it is also suspected that the presence of rowcropped vegetables can challenge REGFLEC performance.

It was found that vertical $\mathrm{CHL}_{1}$ gradient profiles within canopies can reduce the capability of remote sensing methods to explain variations in $\mathrm{LAI}, \mathrm{CHL}_{\mathrm{c}}$ and $\mathrm{N}_{\mathrm{c}}$. The existence of vertical $\mathrm{CHL}_{1}$ gradient profiles violates the assumptions of CRTMs, including the ACRM used by REGFLEC, but also affected the SVIs. The current study used homogeneous canopies without positive or negative $\mathrm{CHL}_{1}$ vertical gradients as reference data to evaluate REGFLEC performance. In the future, field spectrometric studies should be designed to examine the effect of $\mathrm{CHL}_{1}$ vertical gradients on spectral canopy reflectance and remote-sensing-based estimations of LAI, $\mathrm{CHL}_{1}$ and $\mathrm{N}_{1}$.

Despite the demonstrated capability of REGFLEC to simulate $\mathrm{CHL}_{1}$ in previous studies, it was not possible to achieve statistically significant results for leaf-scale predictions in this study. The ill-posed nature of the model inversion significantly complicates the process of extracting the $\mathrm{CHL}_{1}$ (and LAI) signal from remote sensing observations. The current study took place in the middle of the growing season, except for DK09 where REGFLEC results were good, and it is expected that the availability of an out-of-season satellite image with larger soil exposure would improve the results.

Results achieved in the current study for $\mathrm{N}_{\mathrm{c}}$ mapping of European agricultural landscapes showed large spatial variations within and between landscapes which are attributed to seasonal variations, extent of agricultural area, different species, and spatial variation in nutrient availability. Such spatial information is important to improve understanding, modelling and upscaling of carbon and nitrogen budgets. With the launch of the European satellite mission Sentinel2 in 2013, new narrowband data opportunities are expected to improve the accuracies of LAI, $\mathrm{CHL}_{1}$ and $\mathrm{N}_{1}$ assessments. With these data, the mapping of seasonal variations in LAI, $\mathrm{CHL}_{1}$ and $\mathrm{N}_{1}$ with a high spatial resolution will be possible. 


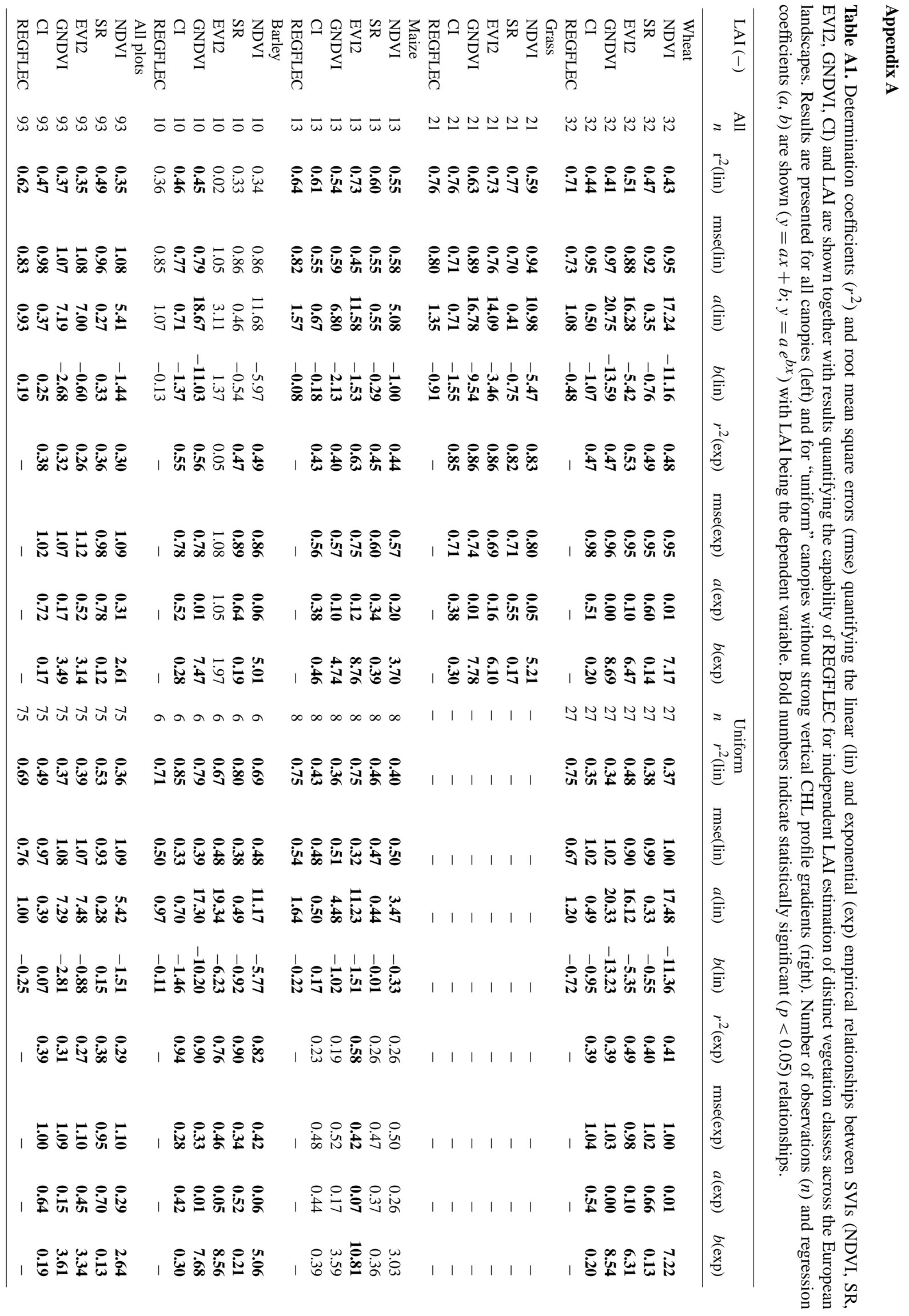




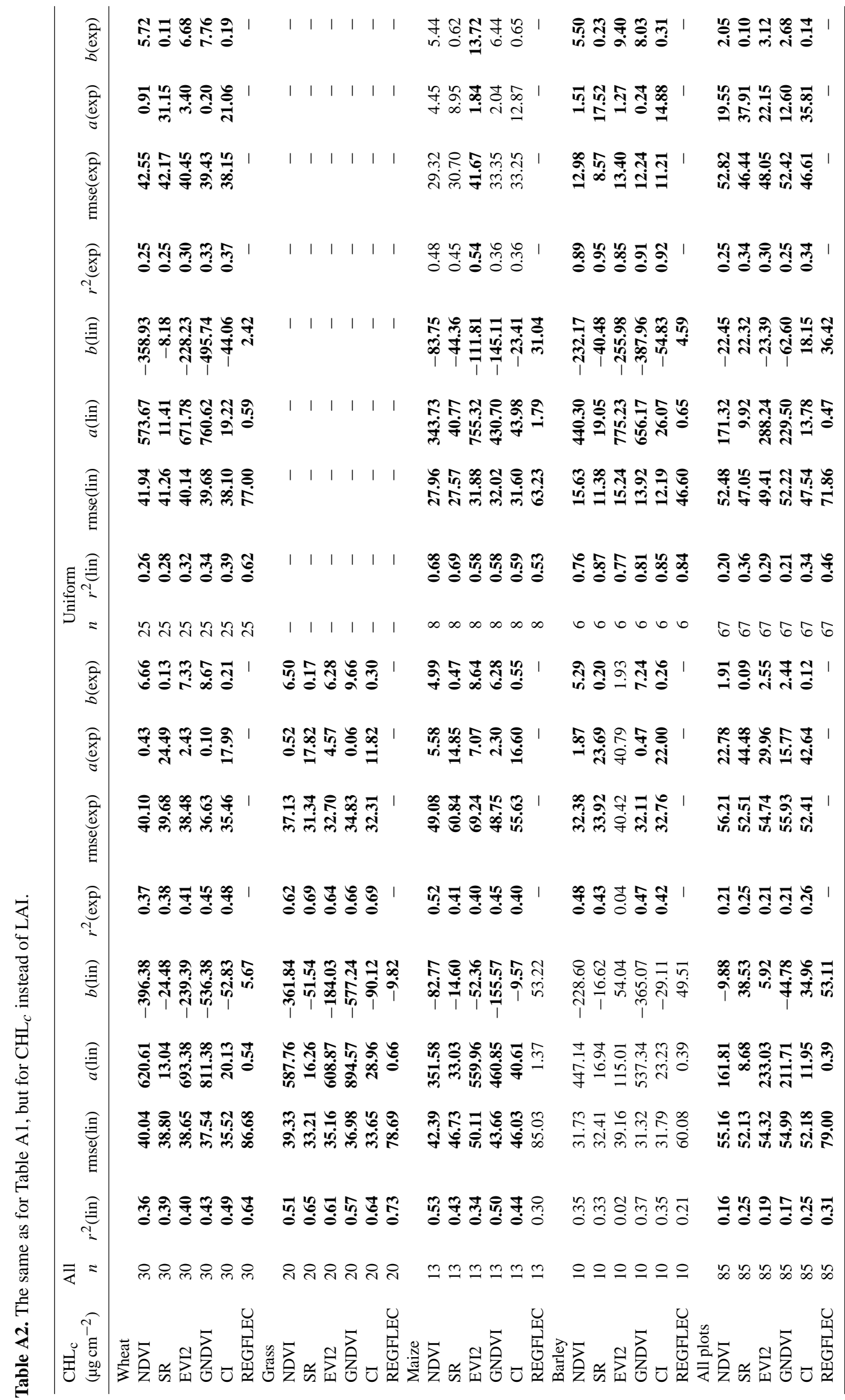




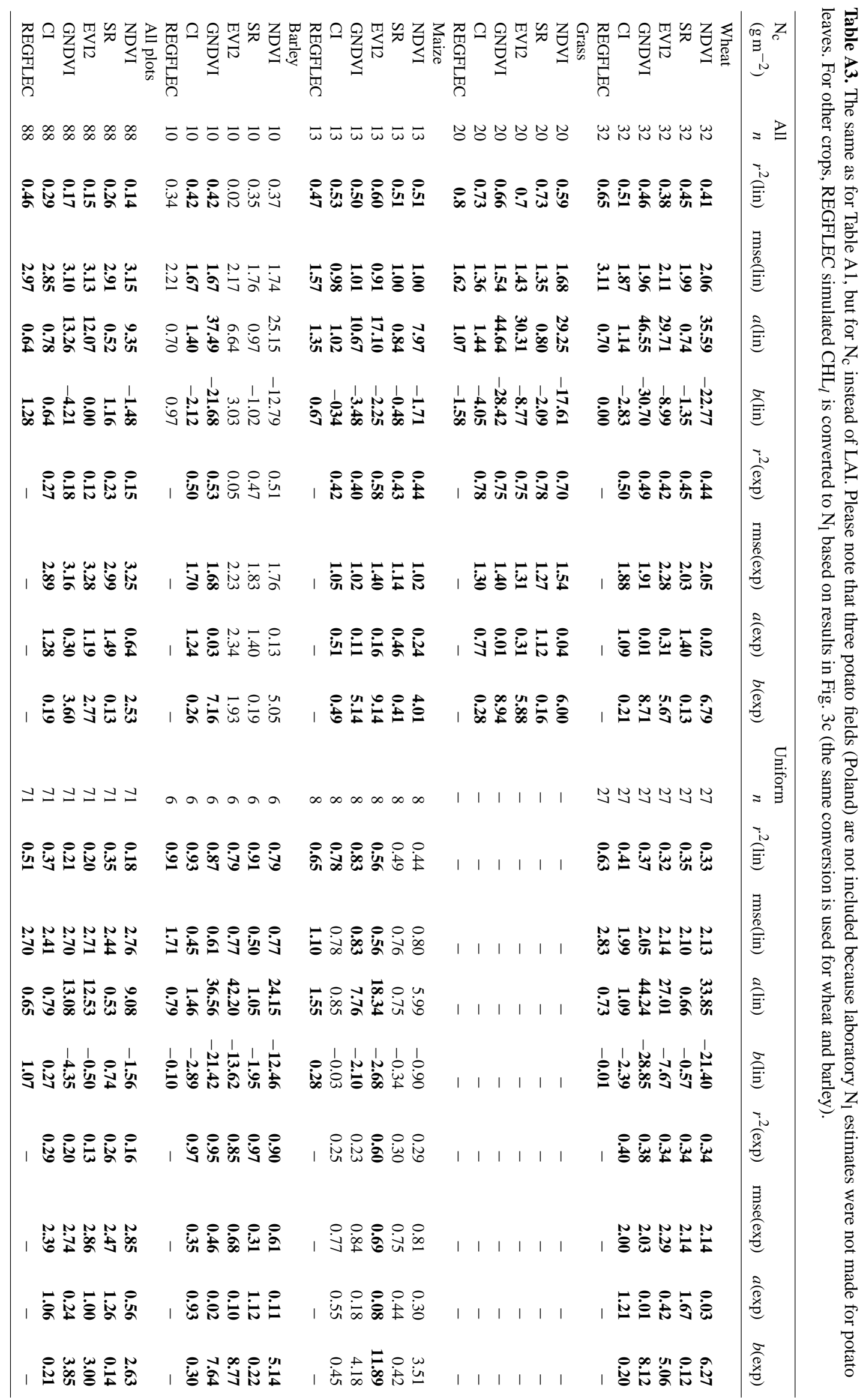




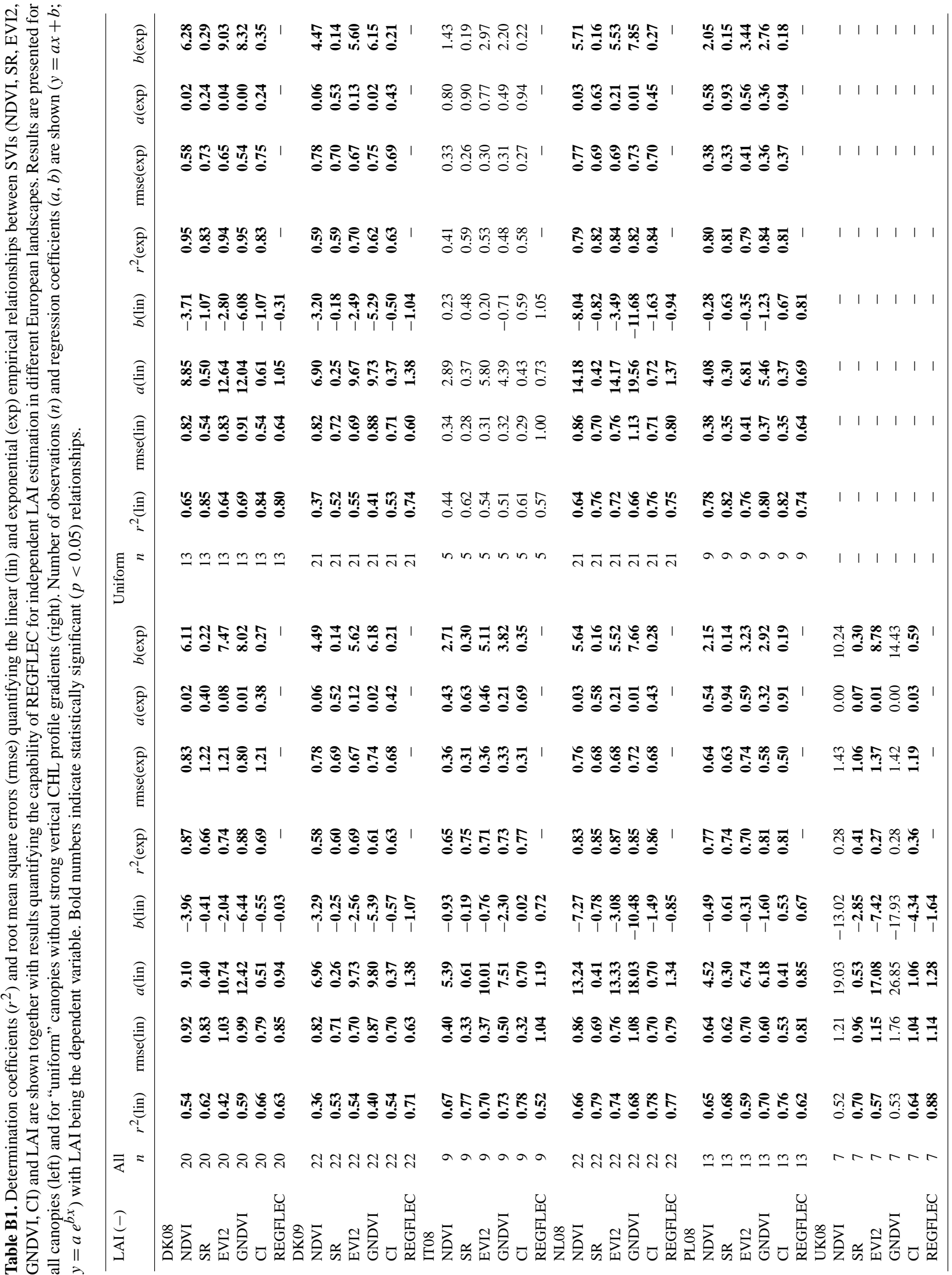




\begin{tabular}{|c|c|c|c|c|c|}
\hline 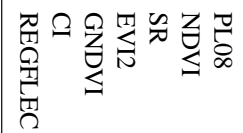 & 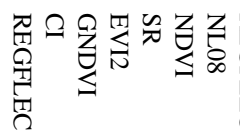 & \multicolumn{3}{|c|}{ 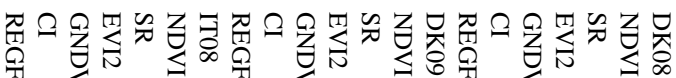 } & 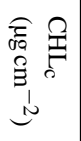 \\
\hline$\varpi \varpi \varpi \varpi \varpi \omega$ & NNNNN N & 060606 & $\simeq \simeq \simeq \simeq \simeq$ & 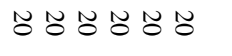 & $=\geqq$ \\
\hline 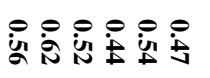 & 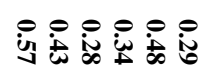 & 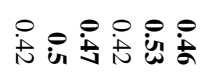 & 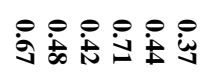 & 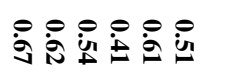 & $\stackrel{i}{E}$ \\
\hline 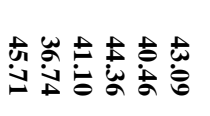 & 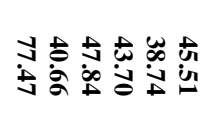 & 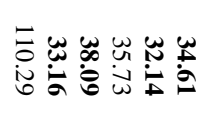 & 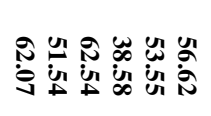 & 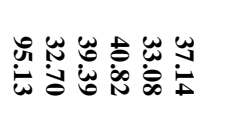 & 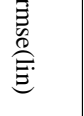 \\
\hline 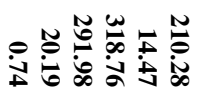 & 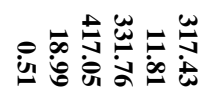 & 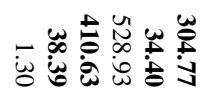 & 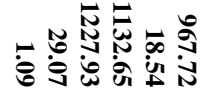 & 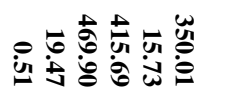 & 官 \\
\hline 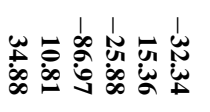 & 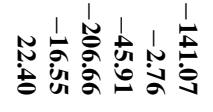 & 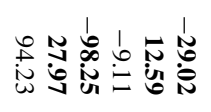 & 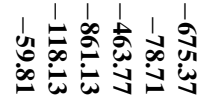 & 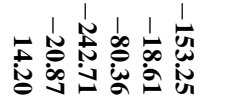 & 产 \\
\hline 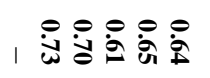 & 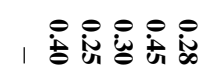 & 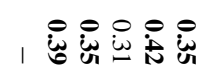 & 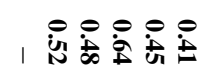 & | & 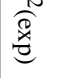 \\
\hline 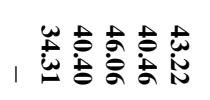 & 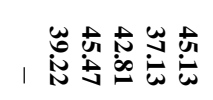 & 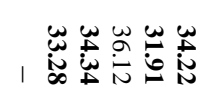 & | & 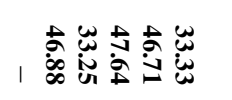 & $\begin{array}{l}\overline{0} \\
0 \\
0 \\
0 \\
0 \\
0 \\
0\end{array}$ \\
\hline I & | & 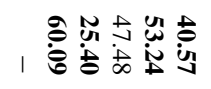 & | & | & 产 \\
\hline 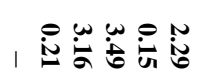 & | & 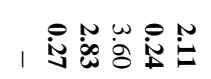 & 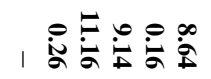 & | & 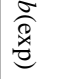 \\
\hline 060606 & $\simeq \simeq \simeq \simeq \simeq$ & urueruer & 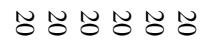 & $\varpi \varpi \bar{\omega} \bar{\omega} \bar{\omega}$ & $=\Xi$ \\
\hline 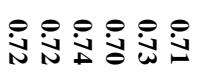 & 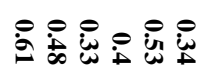 & 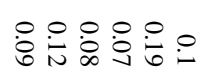 & 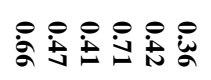 & 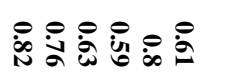 & 養 \\
\hline 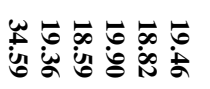 & 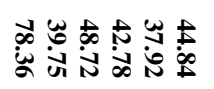 & 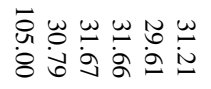 & 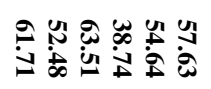 & 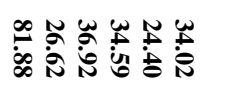 & 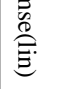 \\
\hline 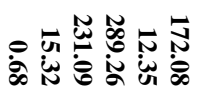 & 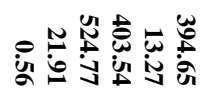 & 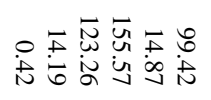 & 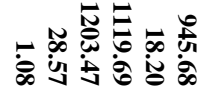 & 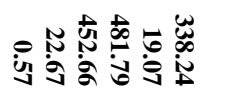 & 产 \\
\hline 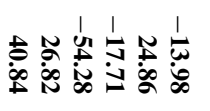 & 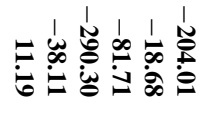 & 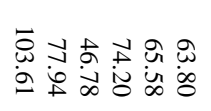 & 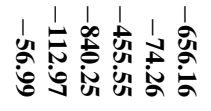 & 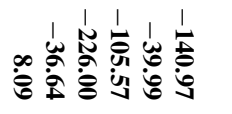 & 它 \\
\hline 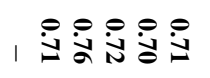 & | & | & | & | & $\frac{\sqrt{0}}{2}$ \\
\hline 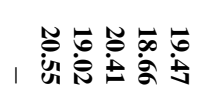 & 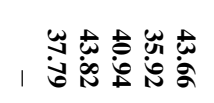 & 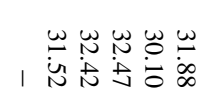 & 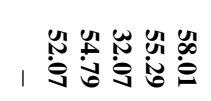 & 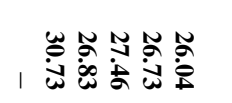 & $\frac{\mathscr{D}}{\mathbb{X}}$ \\
\hline । & | & 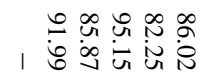 & । & 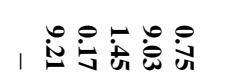 & 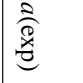 \\
\hline 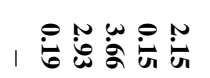 & 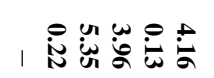 & 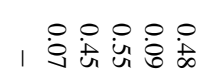 & 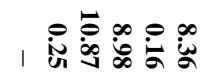 & | & $\begin{array}{l}\frac{\sigma}{8} \\
\frac{\sigma}{2}\end{array}$ \\
\hline
\end{tabular}




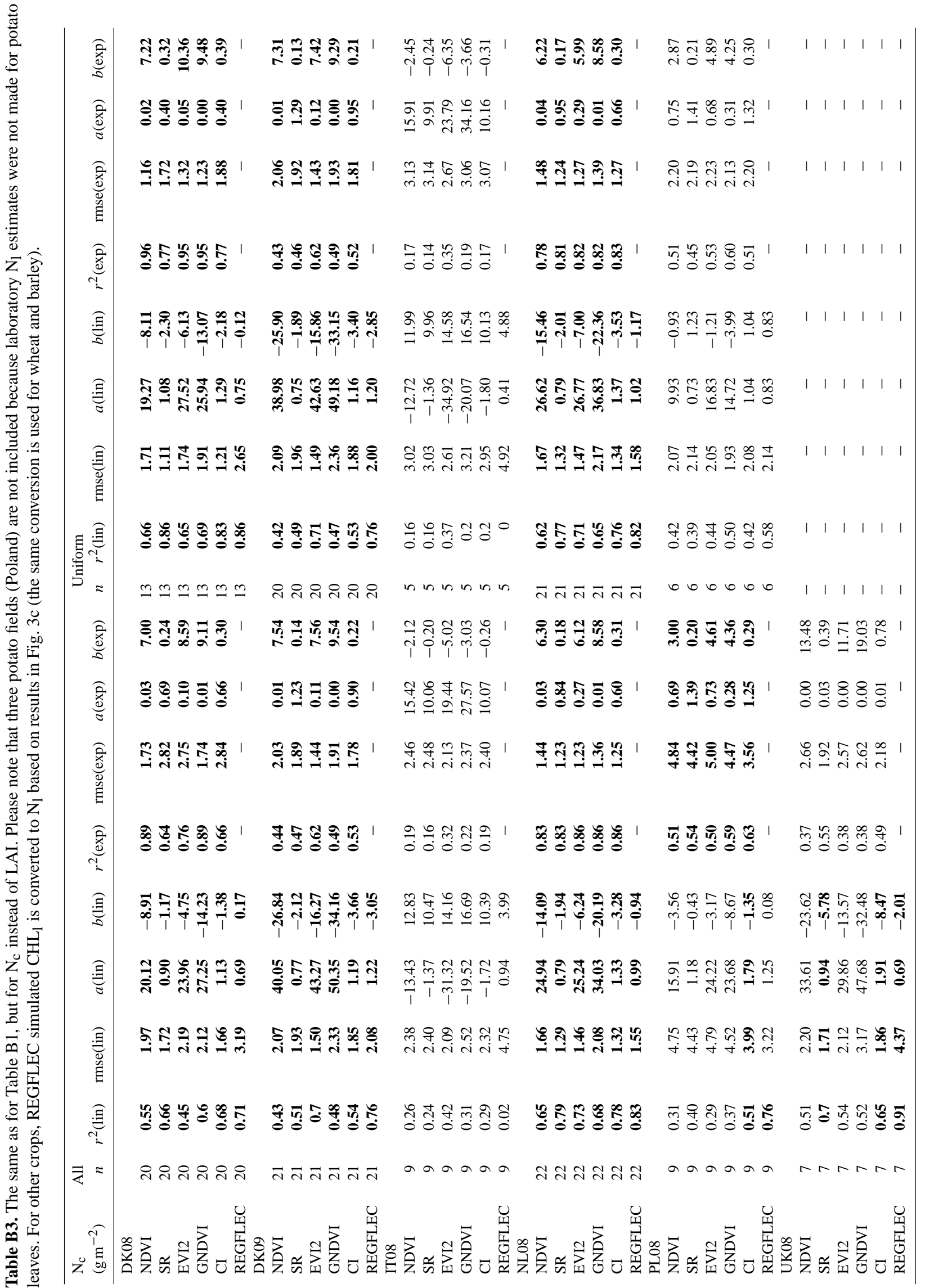




\section{Supplementary material related to this article is available online at http://www.biogeosciences.net/10/ 6279/2013/bg-10-6279-2013-supplement.zip.}

Acknowledgements. This study is a contribution to the EU Integrated Project NitroEurope (www.nitroeurope.eu), which was funded by the European Commission (project 17841-2), and to the project "Remote sensing of leaf nutrition and its incorporation for biochemical and environmental modelling of crop photosynthesis and evapotranspiration", funded by the Danish National Research Council (project 23-04-00156). The study is also affiliated to the project "Ecosystems Surface Exchange of Greenhouse Gases in an Environment of Changing Anthropogenic and Climatic Forcing" (ECOCLIM), financed by the Danish Strategic Research Council (project 10-093901). Financial support by Spot Image, now Astrium GeoInformation Services, to acquire SPOT satellite images is gratefully acknowledged. The authors would also like to acknowledge the European Commission for use of the ESDB soil map, and we would like to acknowledge the use of free MODIS data downloaded from the NASA EOSDIS data centre, ORNLDAAC. Finally, but not least, we would like to thank the farmers and landowners within the NitroEurope landscapes for their kind collaboration and permissions to make measurements in their fields.

Edited by: S. Reis

\section{References}

Astrium: The SPOT Satellites, http://www.astrium-geo.com/en/ 192-the-spot-satellites, 2012

Atzberger, C. and Richter, K.: Spatially constrained inversion of radiative transfer models for improved lai mapping from future sentinel-2 imagery, Remote Sens. Environ., 120, 208-218, doi:10.1016/j.rse.2011.10.035, 2012.

Atzberger, C., Guerif, M., Baret, F., and Werner, W.: Comparative analysis of three chemometric techniques for the spectroradiometric assessment of canopy chlorophyll content in winter wheat, Comp. Electron. Agr., 73, 165-173, doi:10.1016/j.compag.2010.05.006, 2010.

Baret, F. and Fourty, T.: Radiometric estimates of nitrogen status in leaves and canopies, in: Diagnosis of the nitrogen status in crops, edited by: G. Lemaire, Berlin, Springer, 201-227, 1997.

Blackburn, G. A.: Spectral indices for estimating photosynthetic pigment concentrations: A test using senescent tree leaves, Internat. J. Remote Sensing, 19, 657-675, doi:10.1080/014311698215919, 1998.

Boegh, E., Soegaard, H., Broge, N., Hasager, C. B., Jensen, N. O., Schelde, K., and Thomsen, A.: Airborne multispectral data for quantifying leaf area index, nitrogen concentration, and photosynthetic efficiency in agriculture, Remote Sens. Environ., 81, 179-193, doi:10.1016/s0034-4257(01)00342-x, 2002.

Boegh, E., Thorsen, M., Butts, M. B., Hansen, S., Christiansen, J. S., Abrahamsen, P., Hasager, C. B., Jensen, N. O., van der Keur, P., Refsgaard, J. C., Schelde, K., Soegaard, H., and Thomsen, A.: Incorporating remote sensing data in physically based dis- tributed agro-hydrological modelling, J. Hydrol., 287, 279-299, doi:10.1016/j.jhydrol.2003.10.018, 2004.

Boegh, E., Poulsen, R. N., Butts, M., Abrahamsen, P., Dellwik, E., Hansen, S., Hasager, C. B., Ibrom, A., Loerup, J. K., Pilegaard, K., and Soegaard, H.: Remote sensing based evapotranspiration and runoff modeling of agricultural, forest and urban flux sites in denmark: From field to macro-scale, J. Hydrol., 377, 300-316, doi:10.1016/j.jhydrol.2009.08.029, 2009.

Broge, N. H. and Leblanc, E.: Comparing prediction power and stability of broadband and hyperspectral vegetation indices for estimation of green leaf area index and canopy chlorophyll density, Remote Sens. Environ., 76, 156-172, doi:10.1016/s00344257(00)00197-8, 2001.

Carlson, T. N. and Ripley, D. A.: On the relation between ndvi, fractional vegetation cover, and leaf area index, Remote Sens. Environ., 62, 241-252, doi:10.1016/s0034-4257(97)00104-1, 1997.

Casa, R., Baret, F., Buis, S., Lopez-Lozano, R., Pascucci, S., Palombo, A., and Jones, H. G.: Estimation of maize canopy properties from remote sensing by inversion of 1-d and 4-d models, Prec. Agr., 11, 319-334, doi:10.1007/s11119-010-9162-9, 2010.

Cellier, P., Bleeker, A., Breuer, L., Dalgaard, T., Dragosits, U., Drouet, J. L., Durand, P., Duretz, S., Hutchings, N., Kros, J., Loubet, B., Oenema, O., Olesen, J. E., Mérot, P., Theobald, M. R., Viaud, V., de Vries, W., and Sutton M. A.: Dispersion and fate of nitrogen in rural landscapes, Chapter 11, in: The European Nitrogen Assessment, edited by: Sutton, M. A., Howard, C. M., Erisman, J. W., Billen, G., Bleeker, A., Grennfelt, P., van Grinsven, H., and Grizzetti, B., 229-248, Cambridge University Press, Cambridge, 2011.

Chen, T. X., van der Werf, G. R., Dolman, A. J., and Groenendijk, M.: Evaluation of cropland maximum light use efficiency using eddy flux measurements in north america and europe, Geophys. Res. Lett., 38, L14707, doi:10.1029/2011g1047533, 2011.

Churkina, G., Zaehle, S., Hughes, J., Viovy, N., Chen, Y., Jung, M., Heumann, B. W., Ramankutty, N., Heimann, M., and Jones, C.: Interactions between nitrogen deposition, land cover conversion, and climate change determine the contemporary carbon balance of europe, Biogeosciences, 7, 2749-2764, doi:10.5194/bg7-2749-2010, 2010.

Ciais, P., Wattenbach, M., Vuichard, N., Smith, P., Piao, S. L., Don, A., Luyssaert, S., Janssens, I. A., Bondeau, A., Dechow, R., Leip, A., Smith, P. C., Beer, C., van der Werf, G. R., Gervois, S., Van Oost, K., Tomelleri, E., Freibauer, A., Schulze, E. D., and Team, C. S.: The european carbon balance. Part 2: Croplands, Glob. Change Biol., 16, 1409-1428, doi:10.1111/j.13652486.2009.02055.x, 2010.

Ciganda, V. S., Gitelson, A. A., and Schepers, J.: How deep does a remote sensor sense? Expression of chlorophyll content in a maize canopy, Remote Sens. Environ., 126, 240-247, doi:10.1016/j.rse.2012.08.019, 2012.

Combal, B., Baret, F., Weiss, M., Trubuil, A., Mace, D., Pragnere, A., Myneni, R., Knyazikhin, Y., and Wang, L.: Retrieval of canopy biophysical variables from bidirectional reflectance - using prior information to solve the ill-posed inverse problem, Remote Sens. Environ., 84, 1-15, doi:10.1016/s00344257(02)00035-4, 2003.

Dalgaard, T., Bienkowski, J. F., Bleeker, A., Drouet, J. L., Durand, P., Dragosits, U., Hutchings, N. J., Kedziora, A., Magliulo, V., Olesen, J. E., Thebald, M. R., Maury, O., Akkal, N., and 
Cellier, P.: Farm nitrogen balances in six European agricultural landscapes - a method for farming system assessment, emission hotspot identification, and mitigation measure evaluation, Submitted to Biogeosciences Speciel Issue, Nitr. Clim. Change, 2012.

Darvishzadeh, R., Skidmore, A., Schlerf, M., and Atzberger, C.: Inversion of a radiative transfer model for estimating vegetation lai and chlorophyll in a heterogeneous grassland, Remote Sens. Environ., 112, 2592-2604, doi:10.1016/j.rse.2007.12.003, 2008.

Dash, J., Curran, P. J., Tallis, M. J., Llewellyn, G. M., Taylor, G., and Snoeij, P.: Validating the meris terrestrial chlorophyll index (mtci) with ground chlorophyll content data at meris spatial resolution, Intern. J. Remote Sens., 31, 5513-5532, doi:10.1080/01431160903376340, 2010.

dePury, D. G. G. and Farquhar, G. D.: Simple scaling of photosynthesis from leaves to canopies without the errors of big-leaf models, Plant Cell Environ., 20, 537-557, doi:10.1111/j.13653040.1997.00094.x, 1997.

Duretz, S., Drouet, J. L., Durand, P., Hutchings, N. J., Theobald, M. R., Salmon-Monviola, J., Dragosits, U., Maury, O., Sutton, M. A., and Cellier, P.: Nitroscape: A model to integrate nitrogen transfers and transformations in rural landscapes, Environ. Pollut., 159, 3162-3170, doi:10.1016/j.envpol.2011.05.005, 2011.

EEA/ETC-LUSI: The European Environment - State and Outlook 2010. Land use. ISBN 978-92-9213-160-9, EEA, Copenhagen, 2010.

ESDB: Joint Research Centre, European Commission, European Soil Portal - Soil Data and Information Systems, http://eusoils. jrc.ec.europa.eu/ESDB_Archive/ESDB/, 2010.

Eurostat: Nitrogen balance in agriculture, http://www.ec.europa.eu/ eurostat/, 2012.

Farquhar, G. D., Caemmerer, S. V., and Berry, J. A.: A biochemicalmodel of photosynthetic $\mathrm{co} 2$ assimilation in leaves of c-3 species, Planta, 149, 78-90, doi:10.1007/bf00386231, 1980.

Field, C. B., Randerson, J. T., and Malmstrom, C. M.: Global net primary production - combining ecology and remotesensing, Remote Sens. Environ., 51, 74-88, doi:10.1016/00344257(94)00066-v, 1995.

Filella, I., Serrano, L., Serra, J., and Penuelas, J.: Evaluating wheat nitrogen status with canopy reflectance indexes and discriminantanalysis, Crop Science, 35, 1400-1405, 1995.

Fitzgerald, G., Rodriguez, D., and O'Leary, G.: Measuring and predicting canopy nitrogen nutrition in wheat using a spectral indexthe canopy chlorophyll content index (ccci), Field Crops Research, 116, 318-324, doi:10.1016/j.fcr.2010.01.010, 2010.

Freschet, G. T., Dias, A. T. C., Ackerly, D. D., Aerts, R., van Bodegom, P. M., Cornwell, W. K., Dong, M., Kurokawa, H., Liu, G. F., Onipchenko, V. G., Ordonez, J. C., Peltzer, D. A., Richardson, S. J., Shidakov, II, Soudzilovskaia, N. A., Tao, J. P., and Cornelissen, J. H. C.: Global to community scale differences in the prevalence of convergent over divergent leaf trait distributions in plant assemblages, Glob. Ecol. Biogeogr., 20, 755-765, doi:10.1111/j.1466-8238.2011.00651.x, 2011.

Garrigues, S., Lacaze, R., Baret, F., Morisette, J. T., Weiss, M., Nickeson, J. E., Fernandes, R., Plummer, S., Shabanov, N. V., Myneni, R. B., Knyazikhin, Y., and Yang, W.: Validation and intercomparison of global leaf area index products derived from remote sensing data, J. Geophys. Res.-Biogeosci., 113, 20, G02028, doi:10.1029/2007jg000635, 2008.
Gitelson, A. A., Kaufman, Y. J., and Merzlyak, M. N.: Use of a green channel in remote sensing of global vegetation from eosmodis, Remote Sens. Environ., 58, 289-298, doi:10.1016/s00344257(96)00072-7, 1996.

Gitelson, A. A., Vina, A., Ciganda, V., Rundquist, D. C., and Arkebauer, T. J.: Remote estimation of canopy chlorophyll content in crops, Geophys. Res. Lett., 32, L08403, doi:10.1029/2005g1022688, 2005.

Godin, C. and Sinoquet, H.: Functional-structural plant modelling, New Phytologist, 166, 705-708, doi:10.1111/j.14698137.2005.01445.x, 2005.

Haboudane, D., Miller, J. R., Pattey, E., Zarco-Tejada, P. J., and Strachan, I. B.: Hyperspectral vegetation indices and novel algorithms for predicting green lai of crop canopies: Modeling and validation in the context of precision agriculture, Remote Sens. Environ., 90, 337-352, doi:10.1016/j.rse.2003.12.013, 2004.

Hallik, L., Niinemets, U., and Kull, O.: Photosynthetic acclimation to light in woody and herbaceous species: A comparison of leaf structure, pigment content and chlorophyll fluorescence characteristics measured in the field, Plant Biol., 14, 88-99, doi:10.1111/j.1438-8677.2011.00472.x, 2012.

Hansen, P. M. and Schjoerring, J. K.: Reflectance measurement of canopy biomass and nitrogen status in wheat crops using normalized difference vegetation indices and partial least squares regression, Remote Sens. Environ., 86, 542-553, doi:10.1016/s0034-4257(03)00131-7, 2003.

Houborg, R. and Anderson, M. C.: Utility of an image-based canopy reflectance modeling tool for remote estimation of lai and leaf chlorophyll content at regional scales, J. Appl. Remote Sens., 3, 033529, doi:10.1117/1.3141522, 2009.

Houborg, R. and Boegh, E.: Mapping leaf chlorophyll and leaf area index using inverse and forward canopy reflectance modeling and SPOT reflectance data, Remote Sens. Environ., 112, 186-202, doi:10.1016/j.rse.2007.04.012, 2008.

Houborg, R., Soegaard, H., and Boegh, E.: Combining vegetation index and model inversion methods for the extraction of key vegetation biophysical parameters using Terra and Aqua MODIS reflectance data, Remote Sens. Environ., 106, 39-58, doi:10.1016/j.rse.2006.07.016, 2007.

Houborg, R., Andersen, M. C., Norman, J. M., Wilson, T., and Meyers, T.: Intercomparison of a "bottom-up" and "top-down" modeling paradigm for estimating carbon and energy fluxes over a variety of vegetative regimes across the US, Agr. Forest Meteorol., 149, 1875-1895, doi:10.1016/j.agrformet.2009.06.014, 2009.

Houborg, R., Anderson, M. C., Daughtry, C. S. T., Kustas, W. P., and Rodell, M.: Using leaf chlorophyll to parameterize lightuse-efficiency within a thermal-based carbon, water and energy exchange model, Remote Sens. Environ., 115, 1694-1705, doi:10.1016/j.rse.2011.02.027, 2011.

Huete, A. R.: A soil-adjusted vegetation index (savi), Remote Sens. Environ., 25, 295-309, doi:10.1016/0034-4257(88)90106$\mathrm{X}, 1988$.

Huete, A., Didan, K., Miura, T., Rodriguez, E. P., Gao, X., and Ferreira, L. G.: Overview of the radiometric and biophysical performance of the modis vegetation indices, Remote Sens. Environ., 83, 195-213, doi:10.1016/s0034-4257(02)00096-2, 2002.

Huete, A. R., Didan, K., Shimabukuro, Y. E., Ratana, P., Saleska, S. R., Hutyra, L. R., Yang, W. Z., Nemani, R. R., and Myneni, R.: 
Amazon rainforests green-up with sunlight in dry season, Geophys. Res. Lett., 33, L06405, doi:10.1029/2005g1025583, 2006.

Jacquemoud, S. and Baret, F.: Prospect - a model of leaf optical-properties spectra, Remote Sens. Environ., 34, 75-91, doi:10.1016/0034-4257(90)90100-z, 1990.

Jacquemoud, S., Bacour, C., Poilve, H., and Frangi, J. P.: Comparison of four radiative transfer models to simulate plant canopies reflectance: Direct and inverse mode, Remote Sens. Environ., 74, 471-481, doi:10.1016/s0034-4257(00)00139-5, 2000.

Jiang, Z. Y., Huete, A. R., Didan, K., and Miura, T.: Development of a two-band enhanced vegetation index without a blue band, Remote Sens. Environ., 112, 3833-3845, doi:10.1016/j.rse.2008.06.006, 2008.

Jung, M., Vetter, M., Herold, M., Churkina, G., Reichstein, M., Zaehle, S., Ciais, P., Viovy, N., Bondeau, A., Chen, Y., Trusilova, K., Feser, F., and Heimann, M.: Uncertainties of modeling gross primary productivity over europe: A systematic study on the effects of using different drivers and terrestrial biosphere models, Global Biogeochem. Cy., 21, 12, Gb4021, doi:10.1029/2006gb002915, 2007

Kattge, J., Knorr, W., Raddatz, T., and Wirth, C.: Quantifying photosynthetic capacity and its relationship to leaf nitrogen content for global-scale terrestrial biosphere models, Glob. Change Biol., 15, 976-991, doi:10.1111/j.1365-2486.2008.01744.x, 2009.

Knyazikhin, Y., Martonchik, J. V., Myneni, R. B., Diner, D. J., and Running, S. W.: Synergistic algorithm for estimating vegetation canopy leaf area index and fraction of absorbed photosynthetically active radiation from modis and misr data, J. Geophys. Res.-Atmos., 103, 32257-32275, doi:10.1029/98jd02462, 1998.

Kotchenova, S. Y., Vermote, E. F., Matarrese, R., and Klemm, F. J.: Validation of a vector version of the 6 s radiative transfer code for atmospheric correction of satellite data. Part i: Path radiance, Appl. Optics, 45, 6762-6774, doi:10.1364/ao.45.006762, 2006.

Kuusk, A.: A two-layer canopy reflectance model, J. Quant. Spect. Radiat. Trans., 71, 1-9, doi:10.1016/s0022-4073(01)00007-3, 2001.

Lichtenthaler, H. K.: Chlorophylls And Carotenoids - Pigments Of Photosynthetic Biomembranes, Methods Enzymol., 148, 350382, 1987.

Main, R., Cho, M. A., Mathieu, R., O’Kennedy, M. M., Ramoelo, A., and Koch, S.: An investigation into robust spectral indices for leaf chlorophyll estimation, Isprs J. Photogramm. Remote Sens., 66, 751-761, doi:10.1016/j.isprsjprs.2011.08.001, 2011.

Markwell, J., Osterman, J. C., and Mitchell, J. L.: Calibration of the Minolta SPAD-502 leaf chlorophyll meter, Photosynt. Res., 46, 467-472, doi:10.1007/bf00032301, 1995.

Massad, R. S., Tuzet, A., Loubet, B., Perrier, A., and Cellier, P.: Model of stomatal ammonia compensation point (stamp) in relation to the plant nitrogen and carbon metabolisms and environmental conditions, Ecological Modelling, 221, 479-494, doi:10.1016/j.ecolmodel.2009.10.029, 2010.

Mattsson, M., Herrmann, B., David, M., Loubet, B., Riedo, M., Theobald, M. R., Sutton, M. A., Bruhn, D., Neftel, A., and Schjoerring, J. K.: Temporal variability in bioassays of the stomatal ammonia compensation point in relation to plant and soil nitrogen parameters in intensively managed grassland, Biogeosciences, 6, 171-179, doi:10.5194/bg-6-171-2009, 2009.

Moors, E. J., Jacobs, C., Jans, W., Supit, I., Kutsch, W. L., Bernhofer, C., Beziat, P., Buchmann, N., Carrara, A., Ceschia, E.,
Elbers, J., Eugster, W., Kruijt, B., Loubet, B., Magliulo, E., Moureaux, C., Olioso, A., Saunders, M., and Soegaard, H.: Variability in carbon exchange of european croplands, Agr. Ecos. Environ., 139, 325-335, doi:10.1016/j.agee.2010.04.013, 2010.

Osborne, B., Saunders, M., Walmsley, D., Jones, M., and Smith, P.: Key questions and uncertainties associated with the assessment of the cropland greenhouse gas balance, Agr. Ecos. Environ., 139, 293-301, doi:10.1016/j.agee.2010.05.009, 2010.

Peel, M. C., Finlayson, B. L., and McMahon, T. A.: Updated world map of the koppen-geiger climate classification, Hydrol. Earth Syst. Sci., 11, 1633-1644, 2007, http://www.hydrol-earth-syst-sci.net/11/1633/2007/.

Peng, Y. and Gitelson, A. A.: Remote estimation of gross primary productivity in soybean and maize based on total crop chlorophyll content, Remote Sens. Environ., 117, 440-448, doi:10.1016/j.rse.2011.10.021, 2012.

Schelde, K., Cellier, P., Bertolini, T., Dalgaard, T., Weidinger, T., Theobald, M. R., and Olesen, J. E.: Spatial and temporal variability of nitrous oxide emissions in a mixed farming landscape of Denmark, Biogeosciences, 9, 2989-3002, doi:10.5194/bg-92989-2012, 2012.

Schulze, E. D., Ciais, P., Luyssaert, S., Schrumpf, M., Janssens, I. A., Thiruchittampalam, B., Theloke, J., Saurat, M., Bringezu, S., Lelieveld, J., Lohila, A., Rebmann, C., Jung, M., Bastviken, D., Abril, G., Grassi, G., Leip, A., Freibauer, A., Kutsch, W., Don, A., Nieschulze, J., Borner, A., Gash, J. H., and Dolman, A. J.: The european carbon balance. Part 4: Integration of carbon and other trace-gas fluxes, Glob. Change Biol., 16, 1451-1469, doi:10.1111/j.1365-2486.2010.02215.x, 2010.

Sims, D. A. and Gamon, J. A.: Relationships between leaf pigment content and spectral reflectance across a wide range of species, leaf structures and developmental stages, Remote Sens. Environ., 81, 337-354, doi:10.1016/s0034-4257(02)00010-x, 2002.

Song, L., Bao, X., Liu, X., Zhang, Y., Christie, P., Fangmeier, A., and Zhang, F.: Nitrogen enrichment enhances the dominance of grasses over forbs in a temperate steppe ecosystem, Biogeosciences, 8, 2341-2350, doi:10.5194/bg-8-2341-2011, 2011.

Sutton, M. A., Nemitz, E., Erisman, J. W., Beier, C., Bahl, K. B., Cellier, P., de Vries, W., Cotrufo, F., Skiba, U., Di Marco, C., Jones, S., Laville, P., Soussana, J. F., Loubet, B., Twigg, M., Famulari, D., Whitehead, J., Gallagher, M. W., Neftel, A., Flechard, C. R., Herrmann, B., Calanca, P. L., Schjoerring, J. K., Daemmgen, U., Horvath, L., Tang, Y. S., Emmett, B. A., Tietema, A., Penuelas, J., Kesik, M., Brueggemann, N., Pilegaard, K., Vesala, T., Campbell, C. L., Olesen, J. E., Dragosits, U., Theobald, M. R., Levy, P., Mobbs, D. C., Milne, R., Viovy, N., Vuichard, N., Smith, J. U., Smith, P., Bergamaschi, P., Fowler, D., and Reis, S.: Challenges in quantifying biosphere-atmosphere exchange of nitrogen species, Environ. Pollut., 150, 125-139, doi:10.1016/j.envpol.2007.04.014, 2007.

Uddling, J., Gelang-Alfredsson, J., Piikki, K., and Pleijel, H.: Evaluating the relationship between leaf chlorophyll concentration and SPAD-502 chlorophyll meter readings, Photosynt. Res., 91, 37-46, doi:10.1007/s11120-006-9077-5, 2007.

Verhoef, W. and Bach, H.: Simulation of sentinel-3 images by fourstream surface-atmosphere radiative transfer modeling in the optical and thermal domains, Remote Sens. Environ., 120, 197207, doi:10.1016/j.rse.2011.10.034, 2012. 
Vermote, E. F., ElSaleous, N., Justice, C. O., Kaufman, Y. J., Privette, J. L., Remer, L., Roger, J. C., and Tanre, D.: Atmospheric correction of visible to middle-infrared eos-modis data over land surfaces: Background, operational algorithm and validation, J. Geophys. Res.-Atmos., 102, 17131-17141, doi:10.1029/97jd00201, 1997.

Vina, A., Gitelson, A. A., Nguy-Robertson, A. L., and Peng, Y.: Comparison of different vegetation indices for the remote assessment of green leaf area index of crops, Remote Sens. Environ., 115, 3468-3478, doi:10.1016/j.rse.2011.08.010, 2011.

Wang, Q. B., Chen, M. J., and Li, Y. C.: Nondestructive and rapid estimation of leaf chlorophyll and nitrogen status of peace lily using a chlorophyll meter, J. Plant Nutrit., 27, 557-569, doi:10.1081/pln-120028878, 2004.

Wattenbach, M., Sus, O., Vuichard, N., Lehuger, S., Gottschalk, P., Li, L. H., Leip, A., Williams, M., Tomelleri, E., Kutsch, W. L., Buchmann, N., Eugster, W., Dietiker, D., Aubinet, M., Ceschia, E., Beziat, P., Grunwald, T., Hastings, A., Osborne, B., Ciais, P., Cellier, P., and Smith, P.: The carbon balance of european croplands: A cross-site comparison of simulation models, Agr. Ecos. Environ., 139, 419-453, doi:10.1016/j.agee.2010.08.004, 2010.
Winterhalter, L., Mistele, B., and Schmidhalter, U.: Assessing the vertical footprint of reflectance measurements to characterize nitrogen uptake and biomass distribution in maize canopies, Field Crops Res., 129, 14-20, doi:10.1016/j.fcr.2012.01.007, 2012.

Yoder, B. J. and Pettigrewcrosby, R. E.: Predicting nitrogen and chlorophyll content and concentrations from reflectance spectra (400-2500 nm) at leaf and canopy scales, Remote Sens. Environ., 53, 199-211, doi:10.1016/0034-4257(95)00135-n, 1995.

Yoder, B. J. and Waring, R. H.: The normalized difference vegetation index of small douglas-fir canopies with varying chlorophyll concentrations, Remote Sens. Environ., 49, 81-91, doi:10.1016/0034-4257(94)90061-2, 1994.

Zhao, M. S., Heinsch, F. A., Nemani, R. R., and Running, S. W.: Improvements of the modis terrestrial gross and net primary production global data set, Remote Sens. Environ., 95, 164-176, doi:10.1016/j.rse.2004.12.011, 2005a.

Zhao, D. L., Reddy, K. R., Kakani, V. G., and Reddy, V. R.: Nitrogen deficiency effects on plant growth, leaf photosynthesis, and hyperspectral reflectance properties of sorghum, European J. Agron., 22, 391-403, doi:10.1016/j.eja.2004.06.005, 2005b. 